ISSN: 0213-2079 - ISSN electrónico: 2386-3889

DOI: https://doi.org/10.14201/shhmo2017391265299

\title{
BANQUEROS ALEMANES DE FELIPE IV: LOS FUGGER JÓVENES Y JULIO CÉSAR SCAZUOLA (1618-1641)
}

\section{Philip IV's German Bankers: The Younger Fugger and Julio César Scazuola (1618-1641)}

Carlos ÁLVAREZ NOGAL

Universidad Carlos III de Madrid

Correo-e: canogal@clio.uc3m.es

RESUMEN: Los Fugger tuvieron dos compañías de negocios trabajando al mismo tiempo en Castilla durante el reinado de Felipe IV. Una compañía nueva se constituyó en 1624 para controlar la Cruzada y firmar contratos de crédito con la Monaquía. Se la conocía en la Corte como los «Fugger jóvenes» y fue capaz de proveer a la Corona con más de 14 millones de ducados durante 16 años. Julio César Scazuola fue su agente en Madrid y se convirtió en uno de los banqueros más importantes de Felipe IV. Esta compañía Fugger desplazó de su puesto a una vieja compañía genovesa utilizando una agresiva estrategia de negociación. Esto nos permite entender el fuerte rechazo que generó entre muchos banqueros genoveses.

Palabras clave: Felipe IV; banqueros; Cruzada; Fugger.

ABSTRACT: The Fugger family had two business companies working at the same time in Castile during the Kingdom of Philip IV. A new company was established in 1624 to control the Cruzada and to sign credit contracts with the Monarchy. It was known in the Court as the «Younger Fuggers» and was able to provide credit to the Council of Finance for more than 14 millions ducats during 16 years. Julio César Scazuola was his main agent in Madrid and became one of the most important Philip IV's bankers. This company ousted an old Genoese firm from his position using an aggressive

(C) Ediciones Universidad de Salamanca / ®@ Stud. his., H. ${ }^{a}$ mod., 39, n. 1 (2017), pp. 265-299 
strategy in the negotiations. It helps to understand the intense hostility showed for many Genoese bankers to this company.

Key words: Philip IV; Bankers; Cruzada; Fugger.

Los Fugger fueron una de las casas de negocios más poderosas e influyentes de Europa a finales de la Edad Media ${ }^{1}$. Partiendo de Augsburgo, al sur de Alemania, sus intereses e inversiones se extendieron por toda Europa gracias a su habilidad como empresarios y por su excelente relación con la dinastía Habsburgo. El apoyo financiero que brindaron a la candidatura imperial de Carlos V les abrió la puerta de la península Ibérica y de sus posesiones americanas ${ }^{2}$. En España no solo lograron recuperar sus préstamos ${ }^{3}$, sino que se hicieron con la gestión de importantes ingresos de la Corona, como los Maestrazgos de las Órdenes Militares y la explotación de la mina de Almadén ${ }^{4}$. Esta última era una actividad básicamente industrial, pero muy ligada a las finanzas reales porque el nuevo método de amalgamación hizo del mercurio la principal materia prima de la minería de plata ${ }^{5}$. La producción y exportación de azogue a América permitía después la llegada de grandes cantidades de metal precioso desde aquel continente. La Corona española encontró en esta casa de negocios alemana el sólido aliado que necesitaba para financiar su imprescindible abastecimiento de mercurio ${ }^{6}$.

1. HäBler, K. von: Die Geschichte der Fugger'schen Handlung in Spanien. Weimar, E. Felber, 1897. Kellenbenz, H.: «Los Fúcar en España y Alemania: un tema de historia comparada», en Actas del Simposio sobre posibilidades y límites de una bistoriografía nacional. 1984, pp. 161-176. Roover, R. D.: Business, Banking and Economic Thought in Late Medieval and Early Modern Europe. Chicago, 1974. Sobre la presencia alemana en los Países Bajos, Harreld, D. J.: High Germans in the Low Countries: German Merchants and Commerce in Golden Age Antwerp. Boston, 2004.

2. Jacobo Fugger aportó el 64 por ciento del coste de la elección y estuvo dispuesto a respaldar el resto. Hering, E.: Los Fúcar. México, 1944, p. 191. Kellenbenz, H.: Los Fugger en España y Portugal hasta 1560. Salamanca, 2000.

3. Carande, R.: Carlos Vy sus banqueros. Barcelona, 1987; UlloA, M.: La Hacienda Real de Castilla en el reinado de Felipe II. Madrid, 1977.

4. Hering, E.: Los Fúcar, pp. 329-331. El primer arriendo fue otorgado por tres años y fue sucesivamente renovado salvo una interrupción a mediados del siglo XVI. GraUlaU, J.: «Finance, Industry and Globalisation in the Early Modern Period: The Example of the Metallic Business of the House of Fugger», Rivista di Studi Politici Internazionali, 300, 2008, pp. 554-598.

5. Castillo Martos, M.: «Bartolomé de Medina introduce la amalgamación en Nuevas España», en CAstillo Martos, M. y LANG, M. F.: Metales preciosos: unión de dos mundos. 1995, pp. 96-105, LANG, M. F.: El monopolio estatal del mercurio en el México colonial. México, 1978.

6. Como pasaban meses desde la entrega del mineral hasta ser abonado con la plata americana, el crédito era imprescindible para financiar esta actividad.

(C) Ediciones Universidad de Salamanca / ®@ Stud. his., H. ${ }^{a}$ mod., 39, n. 1 (2017), pp. 265-299 
Hace unos años, parafraseando a Domínguez Ortiz , Ruiz Martín volvía a señalar que, en España, los Fugger eran más conocidos en sus fases de prosperidad que en las de postración ${ }^{8}$. Una afirmación que aún hoy sigue siendo válida, pues sabemos muy poco de su estrategia de negocio, de sus actividades financieras y de su quiebra, acontecida a mediados del siglo Xvir. Los investigadores que hasta ahora se han ocupado de las finanzas de la Corona han estudiado a los Fugger siempre junto al resto de banqueros de Felipe IV, sin que exista un estudio específico sobre los negocios que esta familia tuvo en Castilla durante ese periodo histórico.

Es conocido que los banqueros más importantes del rey en la primera mitad del siglo XVII eran genoveses, tanto por su número, como por el volumen de sus préstamos. Sin embargo, la Corona siempre estuvo interesada en contar con agentes financieros de distinto origen con el fin de fomentar entre ellos una sana competencia que le facilitase el crédito9. Se pensaba que, si existía y se fomentaba una cierta rivalidad, los banqueros rebajarían las exigencias y condiciones de los servicios que ofrecían. Por este motivo, los Fugger siempre fueron un importante aliado de la Corona y una alternativa al poder y prestigio de que gozaban los genoveses en los mercados de internacionales de crédito. Otra cosa muy distinta era el interés que ellos pudieran tener en las finanzas del rey de España en determinados momentos, o su capacidad para dirigir de forma eficiente una compañía a más de 2.000 kilómetros de distancia de su sede en Alemania.

El reinado de Felipe IV supuso el final de la presencia de los Fugger en España, pero paradójicamente también fue el único en el que, durante más de diez años, hubo dos compañías de esa misma familia trabajando para la Real Hacienda y compitiendo entre sí. Una imagen más de la complejidad de las finanzas españolas durante este periodo y de sus interlocutores $\operatorname{crediticios}^{10}$.

Este trabajo pretende ser una primera aproximación al estudio de una compañía de negocios prácticamente desconocida hasta ahora: los «Fugger jóvenes» ${ }^{11}$. Su

7. Domínguez Ortiz, A.: Política y Hacienda de Felipe IV. Madrid, 1960, p. 135.

8. Ruiz Martín, F.: Las finanzas de la monarquia hispánica en tiempos de Felipe IV (16211665). Madrid, 1990, p. 62.

9. Álvarez Nogal, C.: «La estrategia de la Real Hacienda en la negociación del crédito de los Austrias», en Bernal, A. M.: Dinero, moneda y crédito en la Monarquía Hispánica. 2000, pp. 437-456, Álvarez Nogal, C.: «The Role Played by Short-run Credit in the Spanish Monarchy's Finances», en Piola Caselli, F. E.: Government Debts and Financial Markets in Europe. 2008, pp. 81-97.

10. Elliott, J. H.: El Conde-Duque de Olivares. Barcelona, 1991.

11. Esta fue la terminología que utilizaron Ruiz Martín y Domínguez Ortiz para referirse a ellos. Con frecuencia, en las discusiones que mantenían los miembros del Consejo de Hacienda se distinguían entre Fúcares antiguos y nuevos.

(C) Ediciones Universidad de Salamanca / ®@ Stud. his., H. ${ }^{a}$ mod., 39, n. 1 (2017), pp. 265-299 
estudio es relevante por tres razones. En primer lugar, se trata de una casa de banca muy poco conocida, pero que jugó un papel fundamental en la década de 1630. Los investigadores han dejado constancia de su intensa relación con la Corona ${ }^{12}$, pero se desconoce su origen y gran parte de su trayectoria. Nunca se la ha estudiado de forma específica y en ocasiones se la vincula con los negocios de la otra compañía Fugger presente en España. En segundo lugar, el estudio de una casa bancaria distinta de las genovesas puede ayudarnos a entender mejor la forma de trabajar de los grandes financieros de la Corona, permitiéndonos hacer comparaciones con otros grupos de banqueros como los genoveses o los portugueses. Por último, estas páginas intentan esclarecer la estrategia del Consejo de Hacienda a la hora de gestionar sus principales ingresos, y también la de los banqueros al negociar con la Corona y tratar con sus competidores.

La información recopilada al investigar esta compañía Fugger en la primera mitad del siglo XviI también muestra cómo la negociación crediticia entre la Monarquía y sus principales financieros no fue únicamente una mera cuestión técnica. No se trataba solo de solicitar una determinada suma de dinero, establecer las fechas para entregar las letras de cambio, fijar el tipo de interés y el coste de cambiar monedas, sino que el éxito de todas estas negociaciones exigía igualmente destreza para tratar en el momento preciso con las personas adecuadas, sabiendo cuándo y a quién había que presentar las propuestas. En la negociación crediticia las personas tuvieron un protagonismo casi tan importante como los millones de escudos y ducados sobre los que se discutía. El éxito o el fracaso de una casa de negocios no dependía solo del volumen de su patrimonio o de la cantidad de dinero que eran capaces de movilizar, sino también de su habilidad y dotes para negociar con la Corona y competir con sus oponentes. Los objetivos personales de los banqueros y de los ministros reales influyeron tanto en la negociación y en las decisiones finales adoptadas, como la rentabilidad y viabilidad económica de los contratos firmados.

Hemos reconstruido los servicios financieros de esta joven compañía Fugger estudiando los contratos de asiento y factoría que se conservan en la sección Contadurías Generales del Archivo General de Simancas, complementando esta información con la que también se conserva en otras secciones de ese mismo archivo, como Consejos y Juntas de Hacienda, Contaduría de Cruzada y la Contaduría Mayor de Cuentas $3^{a}$ época, y con documentación notarial del Archivo Histórico de Protocolos de Madrid.

12. Domínguez Ortiz, A.: Política y Hacienda de Felipe IV. Madrid, 1960. Carlos Morales, C. J. D.: El precio del dinero dinástico: Endeudamiento y crisis financieras en la España de los Austrias, 1557-1647. Madrid, 2016, RuIz Martín, F.: Las finanzas de la monarquía hispánica en tiempos de Felipe IV (1621-1665), pp. 184-196.

(C) Ediciones Universidad de Salamanca / ®@ Stud. his., H. ${ }^{a}$ mod., 39, n. 1 (2017), pp. 265-299 


\section{Los Fugger Jóvenes (1624-1637)}

Los propietarios de las dos compañías Fugger presentes en España durante el reinado de Felipe IV eran descendientes de Antón Fugger, quien en 1525 había sucedido a su tío Jacobo II al frente de su compañía de negocios ${ }^{13}$. Antón fortaleció sus relaciones con el Emperador Carlos V permitiéndole ampliar sus operaciones en Castilla y hacerse con el arrendamiento de los Maestrazgos de las Ordenes Militares ${ }^{14}$. Al morir Antón en 1560 surgieron los primeros problemas entre la Real Hacienda y sus herederos. Algunas estimaciones realizadas solo tres años más tarde hablaban de una deuda del rey con la compañía de casi tres millones de ducados. También estalló entonces el primer gran conflicto familiar que condujo a la primera división del negocio ${ }^{15}$. Los descendientes de Marcus Fugger continuaron al frente de la compañía en España, mientras que los hijos de Georg II abrieron la suya propia en Alemania ${ }^{16}$.

La compañía castellana fue cambiando de nombre a medida que moría alguno de sus socios y se producía una reestructuración, aunque para la Corona siempre fueron los «Fucar» o «Fucares» ${ }^{17}$. A principios del siglo XVII la compañía se denominaba «Marcos y Cristóbal Fúcar, hermanos». Los dos eran nietos de Antón Fugger y vástagos de su segundo hijo, $\mathrm{Hans}^{18}$. Marcos falleció en la década de 1620, dejando el negocio en manos de los hijos de Cristóbal, los condes Juan Ernesto y Otón Enrique, que desde entonces llamaron a la compañía: «Herederos de Marcos y Cristóbal Fúcar, hermanos».

13. Kellenbenz, H.: «Los Fugger en España en la época de Felipe II. ¿Fue un buen negocio el arrendamiento de los maestrazgos después de 1562?», en OTAZu, A.: Dinero y Crédito (siglos XVI al XIX). 1978, pp. 19-36. STEINMETZ, G.: The Richest Man who Ever Lived. The Life and Times of Jacob Fugger. Nueva York, 2015.

14. Idem, pp. 28-29.

15. La disputa enfrentó a Hans Jakob Fugger con sus primos Marx y Hans. KarG, F.: «Jacob Fugger, comerciante, banquero, fundador. Los archivos Fugger», en SÁnCHEZ del BarRIO, A.: Francesco Datini, 1335-1410, Jacob Fugger, 1459-1525, Simón Ruiz, 1525-1597: los legados histórico artísticos y documentales de tres grandes hombres de negocios. 2009, pp. 135-152. Un árbol genealógico en Hering, E.: Los Fúcar, p. 361.

16. Domínguez Ortiz, A.: Política y Hacienda de Felipe IV, p. 136. Ruiz Martín, H.: Las finanzas de la monarquía hispánica en tiempos de Felipe IV (1621-1665), pp. 62-63. KeLLENBENZ, «Los Fugger en España en la época de Felipe II. ¿Fue un buen negocio el arrendamiento de los maestrazgos después de 1562?», pp. 34-35.

17. Es la castellanización de Fugger y el nombre con el que aparecen en la mayor parte de los documentos.

18. Una semblanza de Juan Ernesto y Otón Enrique en Aldea Vaquero, Q.: España y Europa en el siglo XVII. Correspondencia de Saavedra Fajardo. Madrid, 1986, tomo I, p. 549. Recoge dos memoriales de los Fúcar. Para la genealogía ver Nebinger, G. y Rieber, A.: Genealogie des Hauses Fugger von der Lilie. Tubinga, 1978, pp. 24-25.

(C) Ediciones Universidad de Salamanca / ®@ Stud. his., H. ${ }^{a}$ mod., 39, n. 1 (2017), pp. 265-299 
Junto a esta empresa Fugger, la heredera de la que Antón había fundado casi cien años antes y aún responsable de los Maestrazgos y Almadén, al comenzar el reinado de Felipe IV apareció en Madrid otra totalmente distinta e independiente. Sobre la base de un primer negocio con el nombre «Juan Gerónimo, Maximiliano y Marquardo Fúcar, hermanos y primo» centrado más en el comercio que en las finanzas, en 1624 sus socios constituyeron otra con el nombre «Condes Gerónimo Fucar, hermano y primo», que logró convertirse en una de las casas de banca más importantes de Felipe IV en la década de 1630. Para poder distinguirla de la rama más veterana, la historiografía la ha denominado tradicionalmente los «Fugger jóvenes» ${ }^{19}$. Sus socios eran hijos de Jacobo III Fugger: Juan, Gerónimo y Maximiliano, (de la línea de Babenhausen-Wellenburg), a quienes se sumó su primo Marquardo Fugger ${ }^{20}$. Todos eran nietos de Antón y, por tanto, primos de Marcos y Cristóbal Fugger. Maximiliano falleció en 1629 y sus hermanos en 1633, dejando solo a Marquardo que terminó disolviendo la compañía poco tiempo después ${ }^{21}$.

La presencia de los Fugger jóvenes en la península Ibérica fue breve en comparación con los más de cien años que estuvo abierta la otra compañía alemana más veterana. Apenas estuvo activa durante 14 años, entre 1624 y 1637. Sin embargo, ese periodo fue similar o incluso superior al de otras importantes compañías bancarias genovesas y portuguesas. En esta época la supervivencia de un negocio no dependía solo de su éxito empresarial, sino también de la supervivencia de sus gestores. Por otra parte, durante el tiempo que coincidieron en Madrid las dos compañías Fugger, la actividad financiera de los más jóvenes fue siempre mucho más intensa y comprometida con las exigencias de la Corona que la de sus familiares más veteranos, tal y como explicaremos más adelante.

$\mathrm{Al}$ igual que en el caso de otros grandes financieros de la Corona, los orígenes de los Fugger jóvenes hay que buscarlos en el comercio. Antes de su constitución formal como compañía de negocios y de ofrecer servicios al rey de España, este grupo de inversores distribuía productos textiles en Castilla. En 1618 una sociedad formada por Maximiliano Fugger, Hans Siegmund Jacklin y, su gestor, Julio César Scazzuoli (el apellido españolizado terminó siendo Scazuola) ${ }^{22}$, importaba

19. Domínguez Ortiz, A.: Política y Hacienda de Felipe IV; Ruiz Martín, F.: Las finanzas de la monarquía bispánica en tiempos de Felipe IV (1621-1665), pp. 63-64.

20. Archivo General Simancas [en adelante AGS], Consejo y Juntas de Hacienda [en adelante CJH], leg. 602, consulta, 10/2/1624. AGS, CJH, leg. 602, consulta, 26/08/1623.

21. Marcoardo Fucar, como aparece en los documentos, era el administrador de la compañía en 1632 y fue quien le extendió un poder a Julio César el 18 de marzo de aquel año. AGS, Contadurías Generales [en adelante CCGG], leg. 128-1, Escritura de cesión, 25/7/1635.

22. Julio César Scazuola Rasari Canucio. Lohman Villena, G.: Los americanos en las ordenes nobiliarias. Madrid, 1993, vol. 2, p. 131. Scazuola había trabajado para los Fugger viejos. Se

(C) Ediciones Universidad de Salamanca / ®@ Stud. his., H. ${ }^{a}$ mod., 39, n. 1 (2017), pp. 265-299 
tejidos de Augsburgo ${ }^{23}$. Gracias a la ambición e iniciativa personal de este último agente, lo que había comenzado como un pequeño negocio comercial terminó convirtiéndose en una pieza clave del sistema financiero diseñado por el condeduque de Olivares.

A diferencia de las compañías genovesas y portuguesas que firmaron asientos con la Corona, los Fugger siempre delegaron la gestión de sus compañías en factores a los que concedían amplios poderes. Los socios capitalistas no residieron en España y se limitaron a vigilar sus resultados desde Alemania. Mientras los Fugger viejos contaron con varios factores a lo largo de su larga trayectoria en la península Ibérica, los jóvenes solo tuvieron uno: Julio César Scazuola.

\section{Los comienzos de La Joven compañía Fugger: el asalto a la Tesorería General de Cruzada}

Al igual que a la vieja compañía Fugger se la ha identificado siempre con la administración de los Maestrazgos y la mina de Almadén, la nueva compañía llegó a España para controlar la venta de bulas de Cruzada. El origen de este ingreso de la Corona está en la prerrogativa que el Papado concedió a los reyes de España a finales de la Edad Media para financiar sus guerras religiosas ${ }^{24}$. Gestionar la Cruzada suponía controlar en régimen de monopolio tanto su predicación, como la venta de indulgencias en Castilla, Aragón, Baleares, Cerdeña y Canarias. Al terminar la conquista de Granada en 1492, los fondos procedentes de la venta de bulas se destinaron a contener la amenaza turca en el Mediterráneo y las guerras de religión en Europa.

La Santa Cruzada tenía un atractivo especial para los banqueros de la Corona española porque era la puerta de acceso al importante volumen de plata que circulaba por España. La bula debía adquirirse siempre pagando con metal precioso, incluso cuando a principios del siglo xvir la moneda de vellón inundó el mercado ${ }^{25}$. Cuando en la década de los años veinte se comprobó que el exceso de cobre entorpecía la venta de bulas porque muchas personas no disponían de monedas de plata, ni podían conseguirlas fácilmente en el mercado, se terminó

le entregó un poder a Andrés Hirus y a Julio César Scazuola para inspeccionar la compañía. AHPNM, 5232, fol. 594. Poder, 27/05/1621.

23. Voltes, P.: «Aportación a la historia de las operaciones de los Fugger en España durante el xviI», Moneda y Crédito, 1961, p. 34. El capital social ascendía a 725.000 florines en 1627.

24. Goñ Gaztambide, J.: Historia de la bula de la Santa Cruzada. Vitoria, 1958.

25. García Guerra, E. M.: Las acuñaciones de moneda de vellón durante el reinado de Felipe III. Madrid, 2000. Motomura, A.: «The Best and Worst of Currencies: Seigniorage and Currency Policy in Spain, 1597-1650», Journal of Economic History, 1, 1994, pp. 104-127.

(C) Ediciones Universidad de Salamanca / ®@ Stud. his., H. ${ }^{a}$ mod., 39, n. 1 (2017), pp. 265-299 
aceptando que el pago se efectuase en vellón, pero incrementando en este caso su precio para compensar así el valor devaluado que tenía la moneda de cobre. En cualquier caso, incluso en esos años de turbulencias monetarias, la Cruzada siguió siendo una vía directa al metal precioso que circulaba por la península Ibérica y uno de los ingresos más constantes de la Real Hacienda ${ }^{26}$.

Consciente de este atractivo, cada seis años, cuando se renovaba el asiento con el banquero que se encargaría de gestionar la Cruzada, se le exigía adelantar una importante provisión anual de dinero en Flandes a cuenta del ingreso que obtendría después vendiendo bulas ${ }^{27}$. A partir del último tercio del siglo xvi este ingreso estuvo casi siempre en manos de financieros genoveses capaces de llevar a cabo este tipo de transferencias de dinero a nivel internacional y con capacidad para poder endeudarse durante varios meses, antes de venderse las indulgencias.

Al comenzar el siglo xvir la Tesorería General de la Cruzada estaba en manos de Sinivaldo Fiesco, uno de los financieros más poderosos del reinado de Felipe III ${ }^{28}$. Al morir en 1619, después de renovar su asiento de Cruzada por quinta vez consecutiva, su hijo Agustín le sucedió al frente del negocio ${ }^{29}$. Contra todo pronóstico, rompiendo una tradición, la Corona le invitó a negociar la renovación del asiento dos años antes de que expirase su contrato. Era una solicitud muy extraña porque legalmente las conversaciones solo podían iniciarse a lo largo del último año del contrato activo, pero desde el Consejo de Hacienda se utilizó como excusa la necesidad de saber lo antes posible con qué fondos podría contar en el futuro.

La juventud e inexperiencia de Agustín Fiesco en el mundo de los negocios financieros y en el funcionamiento de la Corte, jugaron en su contra. El inconsciente banquero genovés no esperaba encontrar competidores a la hora de renovar el asiento. Lo único que le extrañaba eran las prisas, pero se sentía respaldado por los más de 30 años que su casa llevaba administrando la Cruzada. ¿Quién podía hacerle sombra? La apertura de negociaciones solo podía iniciarse si Agustín daba

26. Andrés Ucendo, J. I. y LANZa García, R.: «Estructura y evolución de los ingresos de la Real Hacienda de Castilla en el siglo XvII», Studia Historica. Historia Moderna, 30, 2008, pp. 147-190.

27. Marcos Martín, A.: «Tráfico de indulgencias, guerra contra infieles y finanzas regias. La bula de Cruzada durante la primera mitad del siglo XvII", en RodríguEz CANCHO, M.: Historia y perspectivas de investigación. Estudios en memoria del profesor Ángel Rodríguez Sánchez. 2002, pp. 227-236; Ojeda NieTo, J.: «La población de Castilla y León en el siglo XviI: un intento de aproximación demográfica a través de la bula de la Santa Cruzada», Studia Historica. Historia Moderna, 22, 2000, pp. 109-144.

28. Carlos Morales, C. J.: «Endeudamiento Dinástico y crisis financieras en tiempo de los Austrias: Las suspensiones de pagos de 1557-1627», Libros de las Cortes, 7, 2013, pp. 99-101.

29. Agustín cedió el puesto de Tesorero General de la Cruzada a Vicencio Squarzafigo, socio de su padre y asentista del rey, para que lo desempeñase en su nombre.

(C) Ediciones Universidad de Salamanca / ®@ Stud. his., H. ${ }^{a}$ mod., 39, n. 1 (2017), pp. 265-299 
su consentimiento, y como alguno había imaginado, el genovés no puso reparos y aceptó sentarse a discutir sobre el siguiente contrato. No tardaría mucho en darse cuenta del grave error que había cometido.

El adelanto de las conversaciones no era casual, ni estaba motivado por las necesidades de planificación de la Real Hacienda, sino que se trataba de un magistral golpe de efecto diseñado por Julio César Scazuola para hacerse con la Cruzada. En 1623 había convencido a varios miembros de los Consejos de Hacienda y Cruzada de que lograría abrir en Madrid una nueva compañía Fugger, independiente de la que ya existía, cuyo establecimiento en la Corte serviría para negociar nuevos asientos con la Corona. Solo pedía a cambio que se le confiase la administración de la Cruzada. Jugó a su favor el profundo disgusto que muchos consejeros sentían hacia la comunidad genovesa, a quienes acusaban de presionar en exceso a la Real Hacienda cuando solicitaba dinero prestado, imponiendo unas condiciones abusivas. Nada más llegar Felipe IV al trono, la Corona hizo un importante esfuerzo por introducir más competencia en la negociación crediticia. Al tiempo que se negociaba con los alemanes, también se exploraba la oportunidad de involucrar en los asientos a nuevos banqueros florentinos y portugueses ${ }^{30}$.

Plenamente confiado en sus posibilidades de renovar el asiento de Cruzada, Agustín Fiesco ofreció una provisión de 350.000 escudos anuales en Flandes, pero exigiendo a cambio una adehala de 80.000 ducados y juros de resguardo adicionales $^{31}$. Una propuesta tacaña $y$, hasta cierto punto, arrogante que no hizo sino confirmar a los miembros del Consejo de Hacienda que era necesario apostar por un cambio. Hasta entonces, Julio César Scazuola había maniobrado en la sombra, sin mostrar públicamente interés por este, ni por otros asientos. Ahora, una vez abierta la negociación de forma oficial presentó su candidatura, pero también solicitó permiso para viajar a Alemania y negociar con una nueva rama familiar de los Fugger una oferta notablemente mejor que la de Fiesco ${ }^{32}$. Para sorpresa de muchos y especialmente de Agustín, recibió la autorización para viajar y obligó a paralizar durante tres meses, entre junio y septiembre, la renovación del asiento.

30. Boyajian, J. O.: Portuguese Bankers at the Court of Spain 1626-1650. Nueva Jersey, 1983; SANZ AYÁn, C.: “"Prestar, regalar y ganar”. Dinero y mecenazgo artístico-cultural en las relaciones entre la Monarquía Hispánica y Florencia (1579-1647)», en Banca, crédito y capital: La Monarquía Hispánica y los antiguos Paises Bajos, 1505-1700. 2006, pp. 459-483.

31. AGS, CJH, leg., 602. Oferta de Agustín Fiesco, 1623. Domínguez Ortiz, A.: Política y Hacienda de Felipe IV, p. 231.

32. AGS, CJH, leg. 602. Memorial, 8/1623. «El qual término se le concedió considerando de quanta importancia sería a su Magestad que una familia tan descansada asentase casa en esta Corte para estos negocios por quanto su bien proceder está conocido en discurso de tanto tiempo».

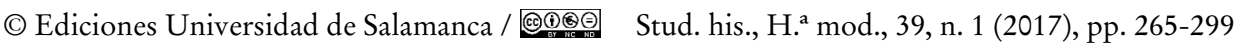


Era una contradicción que la Corona quisiera adelantar casi dos años la renovación del asiento y que, nada más comenzar las conversaciones, las paralizase indefinidamente. En realidad, este aplazamiento no era nada casual, sino parte de la estrategia de Scazuola. El bloqueo supuso un enorme desplante a la casa de Agustín Fiesco y abrió en la Corte un amplio elenco de conjeturas sobre la situación real de su negocio y su relación con la Real Hacienda. Mientras Scazuola empleaba todo el verano en visitar Alemania, circularon muchos rumores en Madrid, cada vez de peor cariz, sobre el futuro del banquero genovés. Unos rumores que acabaron minando su reputación ${ }^{33}$. Muchos se preguntaban por qué la Corona dudaba a la hora de renovarle el asiento. Temiendo problemas de liquidez, sus clientes comenzaron a reclamarle los depósitos que le habían confiado y algunos dejaron de tratar con él. Incluso hubo tesoreros de Cruzada que se negaron a transferirle más dinero hasta no tener garantías de que iba a continuar al frente de la Tesorería General. Agustín suplicó ante el Consejo en diversas ocasiones y de distintas formas que continuase la negociación del asiento, pero sus visitas al palacio real buscando aliados resultaron vanas. La Corona esperó a que Scazuola regresara de Alemania para escuchar su oferta.

El plan trazado por el factor alemán salió conforme a lo previsto. Regresó con el apoyo de los Fugger para pujar hasta donde fuese necesario y lo hizo de forma gradual. Primero ofreció 400.000 escudos, conformándose con la mitad de adehala que solicitaba Fiesco y renunciando a tener juros de resguardo ${ }^{34}$. Frente a esta oferta, los 350.000 escudos ofrecidos por Agustín sonaban ridículos, pero lo peor era que a medida que pasaban las semanas, su crédito se iba deteriorando cada vez más. Las sucesivas ofertas que hizo el banquero genovés fueron siempre replicadas y mejoradas por Scazuola de forma inmediata y sin titubeos. El 11 de enero de 1624, Agustín y su hermano Francisco ofrecieron a la desesperada una provisión de 900.000 escudos y ducados en Flandes y España, pero al día siguiente Julio César subió su apuesta a un millón, conformándose con un interés del 7\% y mostrándose dispuesto a llegar a 1.200 .000 si se le abonaban intereses del $8 \%{ }^{35}$. Por entonces, la reputación de Fiesco estaba ya tan dañada que no solo tenía dificultades

33. AGS, CJH, leg. 602. Memorial Agustín Fiesco, 28/8/1623.

34. AGS, CJH, leg. 602. Memoriales, 26, 28 y 30/8/1623. Primero ofreció 400.000 escudos, pero el 28 de agosto lo incrementó a 430.000 escudos y dos días más tarde hasta los 500.000 escudos. En noviembre ofreció 800.000 escudos y ducados en Flandes y España, el 5 de enero los subió a 850.000 y el 11 de enero hasta 900.000. AGS, CJH, leg. 602. Relación documentos $3 / 1624$

35. AGS, CJH, leg. 602. Relación documentos 3/1624.

(C) Ediciones Universidad de Salamanca / ®@ Stud. his., H. ${ }^{a}$ mod., 39, n. 1 (2017), pp. 265-299 
para competir por la renovación del asiento, sino que ni siquiera tenía fuerzas para finalizar el contrato que aún estaba vigente a su nombre ${ }^{36}$.

El 7 de febrero de 1624 Agustín Fiesco notificó a la Junta su renuncia a seguir negociando, permitiendo que se hiciese oficial el traspaso de la administración de la Cruzada a la nueva compañía Fugger. Ese mismo día Agustín se declaró en quiebra y el Consejo de Hacienda, reunido de urgencia, ordenó la confiscación inmediata de todos sus bienes para que no se fugase con dinero de la Real Hacienda ${ }^{37}$. Su salida de los negocios fue dramática. Temiendo quedarse sin nada, escondió apresuradamente unos cofres con joyas y monedas, y corrió a refugiarse en la casa del embajador de Francia. Allí lo apresaron gracias a la denuncia de un criado de su hermano Francisco. El marqués de los Balbases, a través de Carlos Spínola, Juan Lucas Palavesín y Vicenzo Squarzafigo, que hasta entonces había sido su principal socio en la gestión de la Cruzada, tuvieron que intervenir en la Corte a su favor ${ }^{38}$.

La apuesta de la Corona por incorporar a esta nueva rama de los Fugger a la negociación crediticia fue previa a la llegada de la compañía a Madrid. Los alemanes solo dieron los pasos necesarios para constituirla una vez que se les confirmó que serían los nuevos responsables del asiento de Cruzada ${ }^{39}$. Tal y como había prometido Scazuola, los Fugger jóvenes llegaron dispuestos no solo a hacerse con la Cruzada, sino también a firmar asientos de dinero, compitiendo con el resto de los banqueros del rey, incluso con sus propios primos, la vieja casa Fugger ${ }^{40}$.

La forma de sustituir a Agustín Fiesco al frente del asiento de Cruzada fue un golpe muy duro para toda la comunidad genovesa en Madrid. El propio Vicencio Squarzafigo resultó afectado por su quiebra y tuvo muchos problemas en la primavera de 1624 para cobrar 100.000 ducados que tenía en libranzas de la Cruzada ${ }^{41}$.

36. En enero algunos genoveses como Bartolomé Spínola y Francisco María Piquinoti le estaban ayudando a cumplir con sus pagos.

37. AGS, CJH, leg. 613. Memorial, 27/03/1624.

38. Almansa y Mendoza, A. D.: Cartas. Novedades de esta corte y avisos recibidos de otras partes, 1621-1626. Madrid, 1886, t. XVII, Carta XVI, sin fecha verano de 1624, p. 299. Cfr. RuIZ MarTín, Las finanzas de la monarquía hispánica en tiempos de Felipe IV (1621-1665), p. 128.

39. Recibió el nombre de «Condes Gerónimo Fúcar, hermano y primo». La primitiva sociedad vinculada a la comercialización textil fue reestructurada incluyendo nuevos socios y ampliando su capital. También abrió una sucursal en Génova, cuyo agente fue Jorge Mayre (al menos entre octubre de 1632 y julio de 1636). AHPNM, 1901, fol. 1579. AHPNM, 7337, fol. 229. Más adelante Mayre se convirtió en administrador de la Cruzada en Cataluña.

40. Su competencia no les impidió colaborar en algunas ocasiones, tal y como hacían muchos genoveses. AGS, CJH, 689. Consulta, 8/01/1632. Ese invierno el Consejo firmó un asiento con los Fugger jóvenes en lugar de hacerlo con la vieja compañía.

41. AGS, CJH, 621. Borrador asiento, 16/08/1626. 
Varios hombres de negocios fueron arrestados en la Corte por no poder pagar sus deudas, y se temió durante varios meses que la crisis siguiese extendiéndose como el fuego, agravando la escasez de crédito y afectando a la capacidad de la Real Hacienda para endeudarse ${ }^{42}$.

$\mathrm{Al}$ margen de las alteraciones en los mercados, muchos banqueros genoveses no olvidarían nunca el desplante que había supuesto dejar quebrar a una de las casas de negocios con más tradición en la Corte, fundada por uno de los banqueros más respetados e importantes de Felipe II y Felipe III. No era habitual que la Corona apostase tan fuerte por una compañía inexistente, pero el trato que recibió Agustín quizá formaba parte de la nueva actitud que el gobierno de Olivares quería imprimir a la negociación crediticia a partir de entonces. Soplaban vientos de cambio y era imprescindible mejorar las condiciones crediticias de la Real Hacienda, aun a costa de perjudicar a algunos de sus antiguos socios financieros. No olvidemos que dos años después de llegar los Fugger jóvenes, se incorporaron a las finanzas reales nuevos banqueros portugueses y florentinos, y un año más tarde se declararía la primera suspensión de consignaciones del reinado ${ }^{43}$. Sin prescindir de aquellos que estuviesen en condiciones de continuar, se buscaron nuevas fortunas y formas de acceder al crédito.

El nuevo asiento de Cruzada gestionado por los «Fugger jóvenes» comenzó el primer domingo de Adviento de $1625^{44}$. Durante seis años gestionaron un ingreso anual de 292.400.000 maravedís (779.733,3 ducados) procedente de la venta de bulas, sin contabilizar las vendidas en los archipiélagos de Canarias y Baleares. Su contrato se asoció a una provisión de 1.000 .000 escudos y ducados en Flandes y España $a^{45}$. Este primer asiento de Cruzada se renovó después en 1631 por otros seis años adicionales ${ }^{46}$, al término de los cuales la compañía alemana decidió finiquitar definitivamente sus negocios en España.

Además de la Cruzada, los Fugger jóvenes también se encargaron de gestionar otros ingresos. La misma red de agentes que vendía bulas por toda la península,

42. AGS, CJH, 602. Consulta, 6/05/1624. Se pidió información a don Alonso de Cabrera, del Consejo y Cámara, juez de la quiebra de don Agustín Fiesco, responsable del arresto en su casa de varios hombres de negocios por no pagar sus deudas.

43. Carlos Morales, C. J.: El precio del dinero dinástico: Endeudamiento y crisis financieras en la España de los Austrias, 1557-1647, pp. 178-180.

44. AHPNM, 5787, fol. 358. Recibo, 19/07/1626. AGS, CMC 3. época, 116. Cuentas, 1637-1643.

45. AGS, CJH, 602. Consulta, 28/4/1624. A pesar de que el servicio de millones prohibía acuñar cobre durante 20 años, se les permitió labrar 300.000 ducados de vellón.

46. AGS, CJH, 802.

(C) Ediciones Universidad de Salamanca / ®@ Stud. his., H. ${ }^{a}$ mod., 39, n. 1 (2017), pp. 265-299 
podía recaudar otras rentas ${ }^{47}$. Nada más crearse el impuesto del papel sellado se hicieron cargo de su administración, teniendo en cuenta su pericia y experiencia con la impresión y distribución de grandes cantidades de papel. Scazuola también se encargó de recaudar la media annata de mercedes, cuyo cargo de Tesorero General ejerció al menos desde 1633. Tanto el papel sellado, como la media annata de mercedes fueron dos ingresos muy importantes para la Corona durante esa década ${ }^{48}$. En 1642, el Consejo de Hacienda, viendo los informes precedentes, calculaba que la media annata rendía unos 500.000 ducados anuales, un tercio de los cuales se cobraba en plata. Esos derechos también se pagaban en América y su importe llegaba a Sevilla junto al resto del dinero del rey en las flotas y galeones ${ }^{49}$.

\section{Los Fugger Jóvenes en Las Finanzas de Felipe IV}

Los «Fugger jóvenes» fueron la primera alternativa seria al influyente y numeroso grupo de genoveses que desde el reinado de Felipe II había dominado la negociación de los asientos de dinero. Su incorporación a la negociación crediticia precedió a la de los financieros portugueses y florentinos. Los «Fugger viejos» se habían ido retirando de las grandes provisiones, aunque de vez en cuando ayudasen con alguna suma si se les insistía. Su actividad se centró en gestionar los Maestrazgos y la mina de Almadén, cuya producción de mercurio empezó a resentirse precisamente en la década de 1630, obligando a la Corona a importar azogue desde Idria (Eslovenia) con la ayuda del asentista genovés Antonio Balbi ${ }^{50}$.

La joven compañía Fugger no dudó en firmar asientos de dinero desde el primer momento ${ }^{51}$. Scazuola era muy consciente de que su privilegiada posición en Madrid, como la del resto de banqueros, dependía de los buenos resultados que consiguiese la compañía, pero sobre todo, de su solvencia y liquidez. Era prioritario ser cauto y aunque como factor tenía plenos poderes, cuando se le

47. Marcos Martín, A.: «Tráfico de indulgencias, guerra contra infieles y finanzas regias. La bula de Cruzada durante la primera mitad del siglo Xviı», en Rodríguez Cancho, M.: Historia y perspectivas de investigación. Estudios en memoria del profesor Ángel Rodríguez Sánchez. 2002, pp. 227-236.

48. SAnZ AyÁn, C.: «El canon a la nobleza en la Monarquía Hispánica. La media anata de mercedes», en Marcos Martín, A.: Hacer historia desde Simancas. Homenaje a José Luis Rodríguez de Diego, pp. 705-726. 2011.

49. AGS, CJH, 819. Informe, 15/07/1641.

50. LANG, M. F.: El monopolio estatal del mercurio en el México colonial, pp. 22-136; Álvarez Nogal, C.: Los banqueros de Felipe IV y los metales preciosos americanos (1621-1665). Madrid, 1997, pp. 81-84; GrENDI, E.: I Balbi. Turín, 1997, pp. 139-142.

51. Ruiz Martín, F.: Las finanzas de la monarquía hispánica en tiempos de Felipe IV (16211665), p. 81.

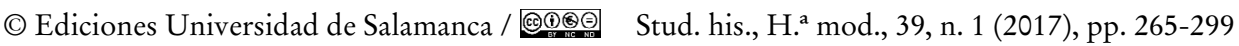


exigía un volumen de crédito elevado o en condiciones demasiado arriesgadas, solía alegar que la última palabra le correspondía a «sus mayores». Por ejemplo, en 1629 la Corona intentó convencerle de que aceptase como consignación de un asiento una partida de juros inicialmente no prevista:

En lo qual él no vino, sino que se escribiese a sus mayores para que viniesen en ello, y para que esto tenga efecto es necesario que el dicho Julio Cesar tenga consentimiento y orden dellos para recibir en juros de millones estos 60.000 ducados que se pusieron en el asiento por consignación de contado ${ }^{52}$.

Resulta difícil elaborar una lista completa de todas las provisiones realizadas por Scazuola a pesar de que existen copias de sus contratos (tabla 1), pues una cosa era lo que se prometía en la negociación o incluso lo que se terminaba firmando $y$, otra muy distinta, lo que llegaba finalmente a cumplirse, tanto por parte del rey como del banquero, especialmente en el siglo XviI.

Scazuola no tardó en experimentar las dificultades que tenía negociar con el Consejo de Hacienda, especialmente en los años previos al decreto de $1627^{53}$. Surgieron problemas casi desde el principio, incluso con lo negociado en el primer asiento de Cruzada. Del millón de escudos y ducados que la compañía había prometido proveer inicialmente, hubo que renunciar a 300.000 varios meses después porque la Real Hacienda no podría abonarle muchas de las consignaciones que le habían prometido.

Tabla 1. Asientos de los Fugger jóvenes y Julio Cesar Scazuola (1624-1639) (totales anuales) ${ }^{54}$

\begin{tabular}{|c|c|l|}
\hline Año & Escudos y ducados & \multicolumn{1}{c|}{ Titular del contrato } \\
\hline 1624 & 1.000 .000 & $\begin{array}{l}\text { Juan Gerónimo, Maximiliano y Marquardo Fucar hermanos } \\
\text { y primo }\end{array}$ \\
\hline 1625 & 804.000 & $\begin{array}{l}\text { Juan Gerónimo, Maximiliano y Marquardo Fucar hermanos } \\
\text { y primo }\end{array}$ \\
\hline
\end{tabular}

52. AGS, CJH, 656. Consulta, 26/02/1629.

53. Cuando se firmó el asiento de 604.000 en 1624, le prometieron que Juan Gerónimo Spínola le pagaría 70.000 ducados, pero nunca se ejecutó, obligándole a acudir en varias ocasiones al Consejo de Hacienda para reclamar esa suma. AGS, CJH, 616, Memorial, 1625.

54. Esta tabla recoge los totales anuales en vellón y plata, resultado de sumar las cantidades que aparecen en los distintos contratos firmados un mismo año. Escudos y ducados se sumaban frecuentemente en muchos contratos considerando, en un redondeo, que el tipo de cambio a maravedís de ambas monedas era el mismo.

(C) Ediciones Universidad de Salamanca / ®@ Stud. his., H. ${ }^{a}$ mod., 39, n. 1 (2017), pp. 265-299 
CARLOS ÁLVAREZ NOGAL

BANQUEROS ALEMANES DE FELIPE IV: LOS FUGGER JÓVENES Y JULIO CÉSAR SCAZUOLA (1618-1641)

\begin{tabular}{|c|c|l|}
\hline Año & Escudos y ducados & \multicolumn{1}{c|}{ Titular del contrato } \\
\hline 1626 & 650.000 & Condes Gerónimo Fucar hermanos y primo \\
\hline 1627 & 600.000 & Condes Gerónimo Fucar hermanos y primo \\
\hline 1628 & 94.241 & Condes Gerónimo Fucar hermanos y primo \\
\hline 1629 & 780.000 & Condes Gerónimo Fucar hermanos y primo \\
\hline 1630 & 390.000 & Condes Gerónimo Fucar hermanos y primo \\
\hline 1631 & 1.752 .000 & Condes Gerónimo Fucar hermanos y primo \\
\hline 1632 & 1.393 .000 & Condes Gerónimo Fucar hermanos y primo \\
\hline 1633 & 2.564 .833 & Condes Gerónimo Fucar hermanos y primo \\
\hline 1634 & 1.579 .000 & Condes Gerónimo Fucar hermanos y primo \\
\hline 1635 & 1.000 .000 & Condes Gerónimo Fucar hermanos y primo \\
\hline 1636 & & \\
\hline 1637 & 562.500 & Julio César Scazuola \\
\hline 1638 & & \\
\hline 1639 & 900.000 & Julio César Scazuola \\
\hline Total & 14.069 .574 & \\
\hline
\end{tabular}

Fuente: AGS, CCGG, 118, 119-1, 120, 121, 122, 123, 124, 125, 126, 127, 128, 129. AGS, CMC $3^{\mathrm{a}}$ época, 116. AGS, CJH, 613, 621, 637, 656, 665, 689, 701, 712, 730. Archivo Histórico de Protocolos Notariales de Madrid [en adelante AHPNM], 1901, 6827.

En diciembre de 1624 el Consejo negoció con cuatro casas de banca un gran asiento de 3.250.000 escudos y ducados, del que los «Fugger jóvenes» asumieron 544.000 en Flandes ${ }^{55}$. Su negociación nos permite entender uno de los incentivos que pudo tener esta rama de la familia Fugger para instalarse en España y hacer negocios con la Corona. Gracias a este asiento, firmado apenas unos meses después del de Cruzada, lograron que el Consejo de Hacienda se comprometiese a abonarles como adehala los más de 190.000 ducados entre principal e intereses acumulados de una vieja deuda que la Real Hacienda tenía pendiente con la familia Fugger desde el siglo xvi. Felipe II había dejado sin pagar a la vieja compañía Fugger una suma cuyos derechos fueron pasando como herencia de unos a otros hasta llegar a los socios de la nueva compañía. Entrar a negociar asientos con la Corona era

55. AGS, CJH, 602. Consulta, 10/12/1624.

(C) Ediciones Universidad de Salamanca / ®@ Stud. his., H. ${ }^{a}$ mod., 39, n. 1 (2017), pp. 265-299 
su mejor opción para recuperar ese dinero ${ }^{56}$. ¿Cómo era posible cobrar en 1625 una suma pendiente desde 1557 cuando algunos banqueros genoveses sufrían para percibir consignaciones incumplidas solo dos años antes? Esta actitud solo puede entenderse como una muestra más de lo decidida que estaba la Corona a incorporar nuevos agentes a la negociación crediticia, aun a costa de cambiar algunas costumbres.

Participar en los asientos del rey fue la llave para acceder a la plata americana. La joven compañía recibió sus primeros 70.000 ducados en la Casa de la Contratación de Sevilla el 24 de enero de 1625. Desde entonces y hasta 1636 se les pagó habitualmente allí una parte de sus consignaciones ${ }^{57}$. Entre 1625 y 1639 la compañía recibió 1.557 .675 ducados de plata, un $48 \%$ de todo el metal precioso entregado a las dos compañías Fugger durante esos años. Siendo una suma importante, no lo es tanto si la comparamos con otros ingresos como la Cruzada o el volumen de crédito que ofreció la compañía a la Real Hacienda durante esos 16 años. De los más de 14 millones de escudos y ducados que pusieron a su disposición, solo recuperaron un $10 \%$ gracias a los metales preciosos americanos, probablemente un porcentaje similar al que percibió el resto de banqueros del rey.

A comienzos de 1626 la compañía alemana participó por primera vez en la negociación de las Provisiones Generales, los asientos más importantes del año ${ }^{58}$. El conde-duque de Olivares logró un compromiso colectivo con los banqueros más importantes para que se encargasen entre todos de una provisión coordinada de 5.980 .000 escudos y ducados ${ }^{59}$. Octavio Centurión y Antonio Balbi asumieron dos quintos del asiento a partes iguales, dejando que los «Fugger jóvenes», Carlos Strata, Esteban Spínola, Vicencio Squarzafigo y Lelio Imbrea aportasen 600.000

56. AGS, CJH, 602. Consulta, 10/12/1624. Las deudas tienen varios orígenes. Una suma negociada por Felipe II en Bruselas en 1557 con Mateo Hortel (Mathias Örtel), representante de los Fuggeren Flandes. Otro asiento tomado con Magno Lucenbergue (Magnus Luzenberger) agente de «Marcos Fúcar y hermanos» en 1591 en Madrid. Otra con «Antonio Fúcar y sobrinos» que sirvieron al emperador en Viena, y varias más de menor importancia. Todas eran deudas originadas por la negociación de la compañía más veterana (Fugger viejos) con la Corona española en el siglo XVI y que habían acabado en manos de esta rama de la familia; KeLLENBENZ, «Los Fugger en España en la época de Felipe II. ¿Fue un buen negocio el arrendamiento de los maestrazgos después de 1562?», en pp. 22-23.

57. Álvarez Nogal, C.: Los banqueros de Felipe IV y los metales preciosos americanos (1621-1665). Apéndices.

58. Carlos Morales, C. J.: El precio del dinero dinástico: Endeudamiento y crisis financieras en la España de los Austrias, 1557-1647, p. 29.

59. Domínguez Ortiz, D.: Política y Hacienda de Felipe IV, p. 31, nota 21. AGS, CJH, 622. Consulta, 1/01/1626.

(C) Ediciones Universidad de Salamanca / ®@ Stud. his., H. ${ }^{a}$ mod., 39, n. 1 (2017), pp. 265-299 
cada uno. El resto quedó en manos de Juan Jerónimo Spínola y Pablo Justiniano. Todos, salvo la compañía de Scazuola, eran genoveses ${ }^{60}$.

Cuando al año siguiente Felipe IV decretó la primera suspensión de consignaciones de su reinado en enero de 1627 solo se excluyó a los «Fugger viejos»; y no tanto por su apellido, sino por su vinculación con la producción de mercurio. A pesar de que la nueva compañía alemana sufrió el decreto como el resto de banqueros genoveses ${ }^{61}$, no parece que les causase un gran daño en su crédito. Además, la suspensión de consignaciones fue rápidamente resuelta y el 11 de junio de ese mismo año la compañía ya había vuelto a firmar una nueva provisión por vía de factoría de 600.000 escudos y ducados.

\section{Servicios Financieros y diplomáticos de la nueVa compañía Fugger}

El papel de Julio César Scazuola en las finanzas de la Corona va mucho más allá de la firma de asientos de dinero. Fue uno de los principales impulsores de la alternativa al «Camino español», la ruta que seguía el dinero en metálico y las tropas que se enviaban habitualmente a Flandes ${ }^{62}$. A finales de 1620 transportar metal precioso a través del Franco Condado se había vuelto muy peligroso por la presión que Francia ejercía en toda esta región y, especialmente, en los pasos fronterizos de los Alpes. Se pensó entonces reforzar la vía marítima a través del Canal de la Mancha, pero el mayor inconveniente era la inseguridad. Para los banqueros alemanes esta posibilidad también era mucho más atractiva porque les permitía evitar Génova y sus ferias de pago. Era imprescindible contar con la colaboración de Inglaterra para lograr que el transporte del metal precioso llegase a su destino sin sobresaltos. Scazuola se entrevistó con Arthur Hopton, embajador inglés en Madrid, y ambos discutieron varias propuestas. Los ingleses querían que, a cambio de su protección, una parte del metal precioso destinado a los Países Bajos se quedase en Londres ${ }^{63}$. El acuerdo alcanzado no solo abrió una nueva ruta para que los banqueros alemanes realizasen sus envíos de metal precioso, sino que también fue aprovechado por otros banqueros genoveses y portugueses para enviar metal precioso a Flandes durante toda la década de $1630^{64}$.

60. AGS, CCGG, 120. Asiento 18/05/1626.

61. AGS, CJH, 665-20-29. Consulta, 2/02/1630. AHPNM, 1901, fol. 3493. Obligación, 4/09/1628. Hubo un pleito con la Real Hacienda sobre si debían ser incluidos en el decreto del 31/01/1627. AGS, CCGG, 125. Copia de cédula, 6/10/1632.

62. Parker, G.: El ejército de Flandes y el Camino Español 1567-1659. Madrid, 1986.

63. TAYloR, H.: «Trade, Neutrality, and the "English Road"», 1630-1648», Economic History Review, 2, 1972, pp. 236-260, p. 244.

64. Marsilio, C.: «Cumplir con cuidado. El mercato del crédito Genovese negli anni 16301640». 2011, p. 812. Conquest, R.: «The State and Commercial Expansion England in the

(C) Ediciones Universidad de Salamanca / ®@ Stud. his., H. ${ }^{a}$ mod., 39, n. 1 (2017), pp. 265-299 
Los ingresos de Cruzada fueron un apoyo importante en la negociación crediticia de la Corona, permitiéndole a la joven compañía Fugger cobrar protagonismo. El Consejo de Hacienda aprovechó su buena reputación para librar sobre ella una parte de las consignaciones que ofrecía cuando firmaba asientos de dinero. A medida que avanzó el reinado, cada vez fue más importante contar con fuentes de ingresos fiables para poder firmar nuevos contratos de crédito y la Cruzada resultaba muy atractiva. Así, por ejemplo, en 1627 estos fondos sirvieron de respaldo a la provisión por vía de factoría de 1.892 .000 escudos y ducados en España y Flandes de un consorcio de genoveses ${ }^{65}$. En 1628 el dinero de la Cruzada se empleó en pagarle a Octavio Centurión, Nuño Díaz Méndez Brito, Duarte Fernández, Manuel Rodríguez de Elvas, Simón Suárez y Manuel de Paz parte del dinero que se les debía por sus asientos ${ }^{66}$, y dos años más tarde también se utilizó la Cruzada para financiar los presidios de España ${ }^{67}$.

Cuando tuvo dificultades, la joven compañía Fugger recibió el apoyo de la Corona para superar sus problemas de liquidez, suministrándole fondos a través del Factor General ${ }^{68}$. Era habitual que algunos de los banqueros del rey respaldasen el crédito de otros agentes financieros cuando surgían problemas. Es cierto que en esta época Castilla no disponía aún de una institución financiera que coordinase, como lo hace hoy un banco central, el rescate de una entidad en apuros o que actuase como prestamista de último recurso, pero hasta cierto punto esa función la ejercía la propia Real Hacienda contando con la ayuda de figuras como el Factor General del rey ${ }^{69}$. Su intervención garantizaba que, con independencia de la calidad que pudieran tener algunos de los ingresos de la Corona en un momento dado, sus banqueros pudieran estar seguros de que siempre cobrarían lo que se les había prometido en los contratos. Aún no disponemos de investigaciones que permitan estimar el coste que tuvo para la Corona apuntalar unos contratos con otros, pero resultó una práctica corriente, especialmente en los momentos más difíciles.

Como ya señalamos, impulsar la competencia entre los banqueros fue uno de los principales objetivos de la Corona desde que comenzó el reinado de Felipe IV y la

years 1642-1688», Journal of European Economic History, 14, 1985, pp. 155-172. SANz Ayán, C.: Los banqueros y la crisis de la Monarquía Hispánica de 1640. Madrid, 2013, p. 276.

65. AHPNM, 1901, fol. 1303. Escritura, 14/08/1628.

66. Archivo General de Indias [en adelante AGI], Contaduría, 364-1. AHPNM, 1901, fol. 3511. Carta de pago, 12/01/1628.

67. AHPNM, 1901, fol. 1321. Poder, 18/08/1628. AGS, CJH, 689. Consulta, 15/02/1632.

68. Álvarez Nogal, C.: «L'argent du Roi et les hommes d'argent», en Dubet, A.: Administrer les finances dnas la Monarchie Espagnole. 2008, pp. 187-198.

69. Álvarez Nogal, C.: «El Factor General del Rey y las Finanzas de la Monarquía Hispánica», Revista de Historia Económica, 3, 1999, pp. 507-539.

(C) Ediciones Universidad de Salamanca / ®@ Stud. his., H. ${ }^{a}$ mod., 39, n. 1 (2017), pp. 265-299 
negociación de algunos asientos muestra con claridad la rivalidad que existía entre las dos compañías Fugger de Madrid. A finales de 1631 Olivares convenció personalmente a Scazuola para que proveyese 840.000 escudos en Flandes y Alemania. En la Corte ya se hablaba de que la suma final de este contrato podría alcanzar incluso los 900.000, pero cuando la compañía presentó sus condiciones en el Consejo de Hacienda, dos de sus miembros más destacados, el marqués de la Puebla, que era el «gobernador» del Consejo desde $1629^{70}$, y Bartolomé Spinola, el Factor General del rey, se negaron a admitirlas. El marqués alegó que la vieja casa de los Fugger había acudido a él solicitándole esa misma provisión, renunciando a la adehala si era necesario. Una muestra de su buena disposición a cooperar con la Real Hacienda, a pesar de que por entonces, la compañía ya tenía ciertas dificultades para endeudarse. Por su parte, el Factor General consideraba que Scazuola era generoso con el tipo de cambio que ofrecía en Flandes, pero su adehala era intolerable. Primero porque iba a cobrar muchas de las consignaciones antes de proveer el dinero y, segundo, porque también reclamaba poder suspender la provisión en el caso de que no se le pagase en los plazos prometidos. La adehala solía ser generosa cuando el riesgo de prestar era elevado, pero esta condición no se cumplía en este contrato. Además, Bartolomé Spínola prefería negociar con los Fugger viejos porque consideraba que era importante darle a esta veterana compañía una nueva oportunidad, teniendo en cuenta lo bien que había servido a la Monarquía durante décadas:

considerado por mayor servicio de Vuestra Majestad y beneficio de su Real Hacienda que esta provisión se encargase a la otra casa de los Fúcares que respecto la calidad della juzga fuera ocasión de volvella a poner en estado de poder servir a Vuestra Majestad ${ }^{71}$.

Muchas veces, la principal dificultad para elegir entre una u otra casa de negocios no era tanto el coste de la provisión, como la puntualidad con la que se ejecutaría $^{72}$. Por este motivo, a pesar de la fuerte enemistad entre Julio César Scazuola y el Factor General del rey, el Consejo optó finalmente por los Fugger jóvenes ${ }^{73}$.

Uno de los principales obstáculos con los que tropezó la negociación crediticia en la década de 1630 fue la moneda de vellón ${ }^{74}$. La incertidumbre generada por

70. Elliott, J.: El Conde-Duque de Olivares, p. 395n.

71. AGS, CJH, 689. Consulta, 6/01/1632.

72. Ibidem. El rey respondió que «se ajuste este asiento siempre que las pagas sean ciertas, que le gustaría mucho poner la casa de los fucares viejos en el estado que decís, aunque otras veces lo he oído y no se ha conseguido». AGS, CJH, 689. Consulta, 8/01/1632.

73. AGS, CJH, 689. Consulta, 6/11/1632.

74. Álvarez Nogal, C.: «Los problemas del vellón en el siglo XviI. ¿Se consiguió abaratar la negociación del crédito imponiendo precios máximos a la plata?», Revista de Historia Económica, 2001, pp. 17-37.

(C) Ediciones Universidad de Salamanca / ®@ Stud. his., H. ${ }^{a}$ mod., 39, n. 1 (2017), pp. 265-299 
la caótica política monetaria castellana terminó por afectar también a los Fugger jóvenes. En octubre de 1632 el rey ordenó a sus contadores mayores de cuentas y a los de Cruzada que revisaran todos los asientos firmados por la compañía «Condes Gerónimo Fucar, hermano y primo» para saber su saldo ${ }^{75}$. La auditoría mostró que hasta el 31 de diciembre de 1630 Julio César aún tenía pendientes por entregar 119.340 ducados, de los que un $60 \%$ eran de plata ${ }^{76}$. Sin embargo, Scazuola había demandado a la Real Hacienda por los 30.000 ducados de pérdidas que había sufrido al tener que vender las bulas en vellón. Al final, en octubre se llegó a un acuerdo para que la compañía enviara a Flandes 45.566 escudos entre octubre y noviembre de $1631^{77}$, saldándose de esta forma su deuda y concediéndole una compensación por las turbulencias que el vellón le había causado en sus negocios.

Gráfico 1. Asientos de los Fugger jóvenes y Julio César Scazoula (1624-1639) (escudos y ducados)

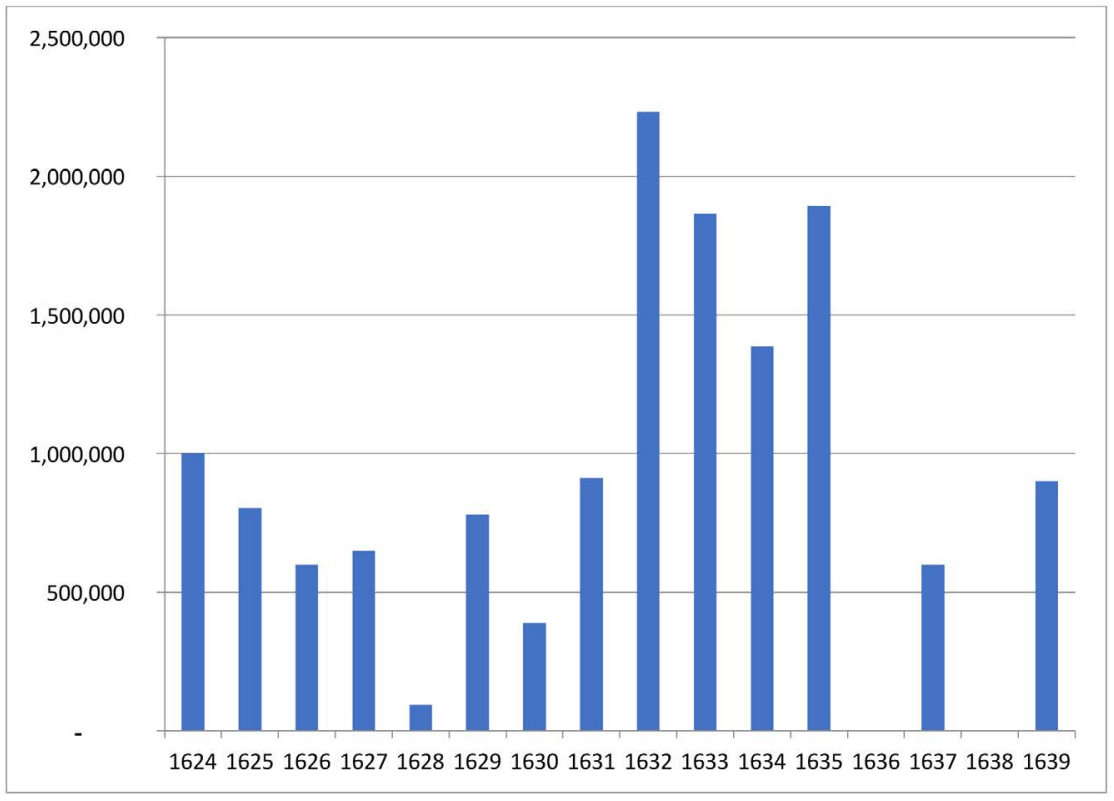

Fuente: Tabla 1.

75. AGS, CCGG, 125. Cédula, 6/10/1632.

76. Esto no incluía las cuentas por la baja del vellón, por las que había una disputa de más de 144 millones de mrs.

77. AGS, CJH, 689. Consulta, 3/10/1632.

(C) Ediciones Universidad de Salamanca / ®@ Stud. his., H. ${ }^{a}$ mod., 39, n. 1 (2017), pp. 265-299 
Cuando en el verano de 1633 se negociaban ya las Provisiones Generales para el año siguiente porque Olivares quería disponer en noviembre de las primeras mesadas ${ }^{78}$, Julio César fue el banquero que más problemas puso a los plazos de reembolso. Quizá porque en esa fecha ya acumulaba retrasos importantes en las consignaciones de asientos firmados previamente, como las que había recibido en Aragón o los 400.000 ducados que se le prometieron en 1631 en el malogrado impuesto de la sal ${ }^{79}$. En mayo de 1632 se le debían más de 886.000 ducados y para respaldarlos se le entregaron como resguardo los ingresos de la recién creada media annata de mercedes ${ }^{80}$, cuya Tesorería General también le fue encomendada.

A pesar de las dificultades que sufrió la compañía en 1633 y del retraso con el que la Corona le entregó aquel año sus consignaciones ${ }^{81}$, el empeño constante de Julio César para seguir adelante hizo que la joven compañía Fugger volviese a estar presente en la negociación de los asientos ordinarios y extraordinarios de 1635, junto al resto de los grandes banqueros: Carlos Strata, Lelio Imbrea, Francisco M. Piquinoti, Duarte Fernández, Manuel de Paz, Jorge de Paz Silveira y Diego Méndez Ximénez ${ }^{82}$. Aquel año Scazuola hizo un esfuerzo similar al de 1632, firmando dos asientos por cerca de 1,9 millones de ducados, aunque más adelante tuvo que pedir ayuda a otros financieros genoveses para llegar a cumplirlo. Juan Lucas Palavesín se hizo cargo de enviar 50.000 ducados a Flandes ${ }^{83}$, mientras Agustín Monella se comprometió con otros 100.000 ducados. Este último le apoyó un mes más tarde con otros 200.000 escudos más (90.000 en Viena y 110.000 en Amberes) ${ }^{84}$. Julio César Scazuola solicitó la autorización de la Corona para oficializar todas estas cesiones, pues la participación les daba derecho a una parte proporcional de los beneficios del contrato.

En 1636, después de que falleciesen varios socios, Marquardo decidió no continuar con la compañía y renunciar a la renovación del asiento de Cruzada ${ }^{85}$,

78. AGS, CJH, 701. Consulta, 23/08/1633.

79. AGS, CCGG, 126. Obligación, 28/04/1633. Sobre el impuesto de la sal: FERNÁNDEZ DE Pinedo, E.: El Censo de la Sal (1631). Hacienda y consumo. Bilbao, 2014.

80. AGS, CCGG, 126. Cédula, 24/05/1632.

81. AGS, CJH, 701. Consulta, 12/08/1633.

82. Archivo Histórico Nacional [en adelante AHN], Consejos-Juros, 273. Informe, 31/10/1635.

83. AGS, CCGG, 128-1. Cédula, 29/07/1635.

84. AGS, CCGG, 128-1. Cédula, 25/07/1635 y 16/08/1635. A Monella se le concedieron 2.000 reales de plata doble por los primeros 100.000 escudos. Los gastos de las transferencias los asumió Scazuola.

85. La liquidación de la compañía Fugger llevaría tiempo por la cantidad de negocios pendientes. En 1637 Julio César confirmó que no había ajustado, ni tampoco tenía previsto finiquitar sus cuentas con la compañía Fugger «porque todo está asentado en sus libros desde el principio de su administración». AGS, Contaduría de Cruzada [en adelante CC], 427. Consulta, 22/04/1637.

(C) Ediciones Universidad de Salamanca / ®@ Stud. his., H. ${ }^{a}$ mod., 39, n. 1 (2017), pp. 265-299 
cuyo contrato expiraba en otoño de $1637^{86}$. El balance de la compañía alemana después de 14 años de servicios financieros había sido muy positivo para la Corona, contabilizándose préstamos y transferencias por más de 14 millones de ducados entre los asientos de dinero y de Cruzada. Hasta 1636, la compañía Fugger debía 50.328 ducados de vellón y también tenía que devolver 244.228 ducados en diferentes consignaciones que tenían en su poder aunque aún no las había cobrado ${ }^{87}$. En total, casi 300.000 ducados que deberían retornar a la Real Hacienda.

\section{LA IMPORTANCIA DE LAS ANTICIPACIONES EN LOS ASIENTOS}

Se sabe muy poco sobre la forma de trabajar de los banqueros del rey de España, en parte porque apenas se ha conservado la documentación privada de sus negocios. Sin embargo, para poder entender su estrategia y la de la Corona en la negociación crediticia necesitamos saber cómo trabajaban y funcionaban esas compañías.

Los genoveses fueron los banqueros más numerosos e importantes de la Corona por el volumen de crédito que ofrecieron. Su acceso a las ferias de cambio les permitía reunir grandes sumas en distintos lugares de Europa ${ }^{88}$. Además, disponían de una extensa red de agentes a muy distintos niveles repartidos por todo el continente y, especialmente, en las ciudades económicamente más activas. Ambos pilares les permitieron captar crédito y realizar transferencias allí donde otros tenían dificultades.

La familia Fugger disponía de un importante volumen de negocio y suficiente prestigio internacional, dada su larga trayectoria comercial, como para captar dinero en distintos lugares de Europa. También atraía con facilidad depósitos bancarios a interés fijo gracias a su fama como empresa solvente ${ }^{89}$. No en vano, sus más de cien años de presencia ininterrumpida en la Corte y el haber superado con éxito los sucesivos decretos de suspensión de consigna-

86. Ruiz Martín, F.: Las finanzas de la monarquia hispánica en tiempos de Felipe IV (16211665), p. 125. Señala que los Fugger jóvenes se retiraron después que los viejos. Domínguez OrTiz, Política y Hacienda de Felipe IV. p. 141. Según Haebler, las dos compañías Fugger se retiraron a la vez por solidaridad, pero Domínguez Ortiz acertó al señalar que los jóvenes desaparecieron primero.

87. AGS, CJH, 791. Cuentas, 29/11/1639.

88. Las ferias eran mercados restringidos. Para intervenir en ellos era necesario contar con un procurador, cuyo número siempre fue limitado. Marsilio, C.: Dove il denaro fa denaro. Glio operatori finanziari genovesi nelle fiere di cambio del XVII sécolo. Novi Ligure, 2008.

89. Ruiz Martín, F.: Las finanzas de la monarquía hispánica en tiempos de Felipe IV (16211665), p. 128.

(C) Ediciones Universidad de Salamanca / @®@@ Stud. his., H. ${ }^{a}$ mod., 39, n. 1 (2017), pp. 265-299 
ciones de Felipe II y Felipe III, les habían otorgado una reputación envidiable. La nueva compañía Fugger aprovechó su apellido y se lanzó desde el primer momento a captar ahorros. La gestión del asiento de Cruzada se lo facilitó mucho, al permitirle disponer de una extensa red de tesorerías repartidas por toda Castilla ${ }^{90}$. Los asientos que firmó Scazuola solían incluir siempre una cláusula concediéndole permiso para recibir dinero en depósito, a cambio de un $5 \%$ de interés anual ${ }^{91}$. En Madrid, banqueros genoveses como Octavio Centurión o Bartolomé Spínola ofrecían en esa época hasta un 7\% anual.

Negociar con un particular una cesión de fondos por un tiempo determinado, permitía disponer de ciertas sumas en buenas condiciones. La otra alternativa era recurrir a lo que en la época se llamaba «tomar dinero a cambio», es decir, pedir prestado en el mercado, normalmente emitiendo una letra girada sobre otra plaza. Una vez vencido el plazo para abonar la letra se volvía a girar de nuevo sobre otra plaza, una y otra vez hasta que el deudor devolviese todo el dinero. Los intereses se iban acumulando y el precio solía ser mucho más elevado que en el caso de los depósitos, lo que era un problema si se pretendía financiar a la Corona a través de asientos, en los que no se solía conceder más de un $8 \%$ anual ${ }^{92}$.

A principios del siglo xviI, en el ámbito crediticio los «Fugger viejos» eran meros intermediarios financieros. La mayor parte del dinero que adelantaban a la Corona española no era suyo, sino de depósitos particulares y de otros banqueros, entre los que también había muchos italianos ${ }^{93}$. El capital propio que ponían los banqueros alemanes apenas llegaba al $20 \%$ del total invertido ${ }^{94}$. Es muy probable que los Fugger jóvenes siguiesen esa misma estrategia. La importancia de los depósitos para sostener sus asientos la confiesa el propio Scazuola en enero de 1626. Ese invierno acudió muy enfadado al Consejo de Hacienda quejándose de que por Madrid circulaba el rumor de que la Corona iba a incautar todos los depósitos de cualquier institución financiera pública o privada. De ser cierto se pondría en peligro su continuidad al servicio de la Corona:

muchos que habían entregado algunas cantidades las han sacado (...) imposibilitando a los dichos Fucares de poder acudir a lo que de parte de Vuestra Majestad últimamente se les ha pedido ${ }^{95}$.

90. El papel de las tesorerías de Cruzada es parte de una investigación en marcha.

91. AGS, CC, 460. Memorial, 2/02/1637.

92. Boyajian, J. O.: Portuguese Bankers at the Court of Spain 1626-1650.

93. Hering, E.: Los Fúcar, pp. 372-373.

94. Voltes, P.: «Aportación a la historia de las operaciones de los Fugger en España durante el XVII», p. 24.

95. AGS, CJH, 621. Consulta, 21/01/1626. 
Según Scazuola la única forma de tranquilizar a los mercados de crédito y acabar con los rumores era expidiendo una cédula en la que el rey asegurase que nunca incautaría ningún depósito.

Los depósitos bancarios eran una parte sobre la que se apoyaba el sistema financiero, pero también tenían sus limitaciones. Nunca fueron suficientes por sí solos para cubrir todo el crédito que necesitaba la Corona, por lo que, además de los depósitos, los banqueros recurrieron habitualmente al descuento de las mismas libranzas que recibían en los asientos ${ }^{96}$. Una práctica habitual en los contratos firmados por Felipe II con sus financieros genoveses y que solo exigía que el banquero dispusiese de cierta liquidez inicial, para poder atender las primeras obligaciones del contrato mientras buscaba por esta vía el resto del dinero. La cláusula de anticipación de muchos asientos permitía este tipo de descuento de libranzas, dándole a los banqueros la oportunidad de jugar con los propios fondos de la Corona, aquellos que ella se comprometía a entregarles en las distintas tesorerías de Castilla. Además, en el caso de los Fugger jóvenes, como ya hemos explicado también contaban con los ingresos de la Cruzada, las rentas del papel sellado y la media anata de mercedes.

Al descontar libranzas la compañía cedía a otros una parte importante de las compensaciones que el Consejo de Hacienda ofrecía en los asientos, pero también reducía su exposición, trasladando el riesgo a esos otros inversores, la mayoría castellanos. Ellos serían quienes esperarían a que la consignación fuese pagada por la Real Hacienda y quienes sufrirían las consecuencias en caso de retrasarse o no pagarse. Los Fugger se quedaban con los beneficios de la adehala de los asientos y con los que reportaba la gestión del metal precioso. Su beneficio no procedía tanto de la cuantía de la comisión o del tipo de interés del asiento, como de las pequeñas comisiones sobre el flujo de dinero que circulaba a través de su compañía.

El descuento anticipado de consignaciones refuerza el papel de intermediación que tenían los banqueros de la Corona. En este caso, conectado con el grupo de tesoreros y receptores de las rentas reales porque eran ellos los que adquirían más libranzas a descuento. Al recaudar importantes sumas solían tener liquidez para intervenir en este tipo de operaciones, y lo hacían sin riesgo porque adquirían las libranzas que ellos mismo debían abonar unos meses más tarde. Entonces, ¿̇por qué la Corona no negoció directamente con ellos en lugar de hacerlo con los banqueros? Lo cierto es que dio ese paso dos décadas más tarde, pero en torno a 1630 el apellido Fugger seguía facilitando la captación de crédito con rapidez y fiabilidad, dada su reputación en el mundo de los negocios. Para la Corona era más sencillo negociar con un banquero que hacerlo con muchos prestamistas a la

96. AGS, CJH, 701. Consulta, 30/06/1633.

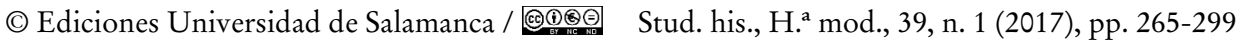


vez. Además, estos quizá podían reunir el volumen de dinero que necesitaba el rey, pero carecían de medios para transferirlo a Flandes o a Alemania.

En los asientos que firmaron los «Fugger jóvenes» queda constancia del permiso concedido por la Corona para vender libranzas. No tanto por una cuestión legal, sino de confianza.

se ayan de poner en cabeza de la persona o personas que el dicho Julio Cesar nombrare en todo o en parte, antes o después de dados los primeros despachos, quedando siempre obligados los dichos fúcares al cumplimiento de los asientos con clausula de que se puedan socorrer anticipadamente de las dichas consignaciones o parte de ella si de los recetores, tesoreros y otras personas a cuyo cargo fueren las pagas, como de otras quelesquier personas, no embargante quelesquier leyes o pregmáticas que aya en contrario a los plazos y precios que pudiere no excediendo de lo que sobre ello esta proveydo por las nuevas ordenanzas echas para el buen gobierno de los negocios de las ferias de Castilla ${ }^{97}$.

Era mucho más fácil para los banqueros encontrar clientes interesados en el descuento de este tipo de efectos si existía una autorización expresa del rey que no dejase lugar a dudas sobre la legalidad de este tipo de transacciones. Además, los Fugger querían ampliar el número de interesados en descontar libranzas para no depender solo de los arrendadores o tesoreros de rentas. Por ejemplo, en 1633 Scazuola pidió ampliar en 300.000 ducados la facultad que le permitía descontar consignaciones, y poder hacerlo

con qualesquier terceros tesoreros y administradores de la Cruzada y de otras rentas, con los premios o intereses que concertare con ellos y hacer acerca de ello los conciertos y escrituras que le pareciere ${ }^{98}$.

\section{La continuidad de Julio César Scazuola en solitario}

Julio César Scazuola fue un hombre de negocios ambicioso y con mucha iniciativa. No solo diseñó la estrategia con la que los Fugger abrieron una segunda compañía en Madrid en 1624 que él mismo gestionó con éxito durante más de una década, sino que una vez que los banqueros alemanes se retiraron en 1636, logró continuar como banquero del rey en solitario ${ }^{99}$. Su contacto con la familia

97. AGS, CJH, 701. Consulta, 30/06/1633.

98. Ibidem. El rey terminó accediendo a la sugerencia del Consejo para ayudarle a cumplir con sus provisiones.

99. AHPNM, 7335, fol. 208. Cuentas de Juan Scoto, 1642. Julio César compró unas casas de Esteban Díaz en la calle de los Majadericos y las arrendó a un cochero en agosto de 1638 por 44 ducados al año.

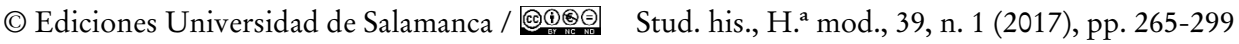


Fugger no se interrumpió, pues siguió encargándose de cobrar las rentas de sus juros y también varias deudas pendientes de la compañía ${ }^{100}$.

La renovación del asiento de Cruzada en 1637 supuso todo un reto para él. Marquardo no tenía bienes en Castilla para poder respaldar un contrato tan importante, pero tampoco era factible que firmase el asiento junto a Julio César Scazuola. Estaba dispuesto a que continuase siendo su factor, pero nunca su socio. La única opción y por la que finalmente optó la Real Hacienda, fue confiarle la Cruzada a Scazuola y a su mujer, quien sí disponía de bienes procedentes de una herencia con el valor suficiente como para utilizarlos como resguardo ${ }^{101}$. Por ese motivo fue el matrimonio quien firmó el nuevo contrato.

El esfuerzo inicial sería importante. Scazuola enviaría 600.000 escudos a Flandes y lo más probable era que tuviese que adelantar otros 300.000 o 350.000 escudos adicionales para cubrir los gastos de impresión, predicación y distribución de la bula, antes de que lograse ingresar algo por su venta. Cifras a las que habría que sumar otros 200.000 ducados en juros o libranzas por la fianza del asiento ${ }^{102}$.

La Corona no dudó en apoyarle porque a finales de la década de los años 30 no podía permitirse el lujo de perder a ningún hombre de negocios, y menos aún uno con la experiencia de Julio César Scazuola. Quizá por eso, a la renovación del asiento de Cruzada se sumó también su continuidad al frente de la media annata de mercedes y de la renta del papel sellado ${ }^{103}$. El único problema era que el factor alemán no disponía del mismo capital, ni del prestigio que tenían los Fugger a la hora de respaldar sus operaciones financieras. Dependía aún más de los depósitos bancarios y de su capacidad para descontar libranzas. Se rumoreaba en el Consejo que uno de sus clientes más importantes era un criado de los Fugger, y que entre sus depósitos contaba con uno «de 70.000 ducados de un cabo que va y viene de Indias». Cuando en 1639 empezó a tener problemas de liquidez, el fiscal de la Junta de media anata le echó la culpa a sus acreedores porque, al tratarse de pequeños ahorradores, entraban en pánico ante cualquier rumor, reclamándole de forma inmediata todo el dinero.

Sus años como factor de los Fugger jóvenes le permitieron incrementar su patrimonio y ascender socialmente. En junio de 1635, Julio César ostentaba los títulos de caballero de la orden de Calatrava y comendador de Molinos y Laguna

100. Voltes, P.: «Aportación a la historia de las operaciones de los Fugger en España durante el XVII», p. 35.

101. AGS, CC, 427. Consulta, 22/04/1637.

102. AGS, CC, 465. Consulta, 22/04/1637.

103. AGS, CJH, 794. Memorial, 19/10/1639. AGS, CJH, 794. Memorial, 30/07/1638.

(C) Ediciones Universidad de Salamanca / ®@ Stud. his., H. ${ }^{a}$ mod., 39, n. 1 (2017), pp. 265-299 
Rota. En 1637 se convirtió también en señor de Tielmes, una población cercana al río Tajuña ${ }^{104}$, aunque nunca llegó a constituir ningún mayorazgo, a diferencia de su mujer que tenía dos por herencia.

La renovación del asiento de Cruzada no estuvo exenta de polémica. Aprovechando la retirada de los Fugger, Bartolomé Spínola entró en la puja ${ }^{105}$, pero no reclamando el contrato para sí mismo porque era incompatible con su cargo de Factor General, sino para su sobrino Gerónimo Gentil. Bartolomé advirtió del agotamiento que ya entonces mostraba la casa de negocios de Scazuola:

por conocerse con evidencia que los que hoy la administran no podían continuar en ella, ny hacer servicio a su Majestad en esta parte por lo que están atrasados en el cumplimiento de las pagas de lo que tenían obligación ${ }^{106}$.

Había serios indicios de la debilidad del banquero alemán. No había justificado los pagos de 1635 y 1636 a cuenta del asiento de Cruzada, a pesar de haber ingresado el importe de las bulas. Un retraso que se unía al que ya acumulaba con los fondos de la media annata de mercedes. Por ese motivo, Bartolomé aconsejó no correr más riesgos y relevarle al frente de la Cruzada. Sin embargo, Scazuola luchó para no perder ni el asiento, ni su Tesorería General. Ofreció primero un adelanto de 600.000 ducados, enviando dos tercios de esa suma a Flandes. Una cifra irreal según Spínola porque sus deudas ya alcanzaban por entonces esa misma cifra. También se responsabilizó de continuar con los negocios cuya titularidad aún seguía a nombre de la compañía Fugger, incluidas algunas provisiones de dinero pendientes.

Antes de tomar una decisión, el Consejo de Hacienda ordenó revisar todas las cuentas de Scazuola, descubriéndose que estaba retrasado en el pago de 1.636.203 escudos, la mayor parte en Flandes, pero también en Viena, Colonia y en los salarios de los embajadores ${ }^{107}$. El Consejo de Cruzada reconocía que en los dos últimos años su reputación se había deteriorado al haberse comprometido en asientos de

104. AHPNM, 5982, fol. 442. Transacción, 19/02/1641. Se hizo con su jurisdicción y adquirió una finca en la que plantó árboles frutales. Esta inversión acabó en un pleito porque Scazuola se negó a abonar al Cardenal-infante, titular de la dignidad arzobispal de Toledo, el diezmo de su producción. El 8 de noviembre de 1639 Julio César aceptó pagar 1/17 parte de los frutos recogidos.

105. Sobre la figura de Bartolomé Spínola: Álvarez Nogal, C.: «El Factor General del Rey y las Finanzas de la Monarquía Hispánica»; Álvarez Nogal, C.: «Las compañías bancarias genovesas en Madrid a comienzos del siglo XVII", Hispania, 219, 2005, pp. 67-90.

106. AGS, CC, 465. Memorial, 16/02/1637.

107. AGS, CC, 465 . Ajuste, $7 / 03 / 1637$.

(C) Ediciones Universidad de Salamanca / ®@ Stud. his., H. ${ }^{a}$ mod., 39, n. 1 (2017), pp. 265-299 
gran envergadura que después no había podido cumplir ${ }^{108}$. El pagador del ejército en Flandes informó de sus retrasos, tanto en los asientos de dinero como en el de la Cruzada, lo que le suponían anualmente a la Real Hacienda un coste adicional del $18 \%$ en concepto de intereses de anticipación ${ }^{109}$.

Julio César se defendió y logró demostrar con diversos justificantes que su deuda no era tan alta y que ya había abonado al menos 1.189 .103 escudos de la cantidad que se le reclamaba, mientras que el resto estaba también en camino. Es más, el 31 de marzo de 1637 el propio presidente del Consejo de Hacienda confirmó con el pagador general de Flandes, don Juan de Lira, que Julio César estaba al día en sus provisiones, y que lo único que le restaba por entregar era la suma que el Consejo acordase con él para reparar los daños que habían causado sus retrasos ${ }^{110}$.

Aunque Bartolomé Spínola se empleó a fondo por minar la reputación de Scazuola, no consiguió convencer a los consejeros de Hacienda y de Cruzada para que eligiesen a su sobrino ${ }^{111}$. Se reconoció que la propuesta de Bartolomé era mucho mejor por sus condiciones y seguridad, pero se optó finalmente por darle continuidad al banquero alemán para evitar una concentración excesiva de poder y dinero en un solo banquero. Existía el temor a que por apoyar este asiento, aunque no fuese su responsable, se resintiese el resto de obligaciones que tenía como Factor General. Además, el Consejo de Hacienda no olvidaba los muchos servicios prestados por Scazuola:

Y no se puede dexar de ponderar que Julio César ha servido a V.Mg. por espacio de 13 o 14 años con mucha puntualidad, haviendose encargado de proveer en este tiempo sumas tan grandes que se dice pasan de más de 20 millones aviendo sido de los que más fácilmente se an convenido en los contratos que con él se han hecho. Y que a doce años que sirve en la Cruzada y oy se trata no de dársela, sino de continuar lo que está exerciendo que en este caso siempre se a de estar por el que posee y que podría causar su total ruina y quiebra el faltarles por ahora la Cruzada ${ }^{112}$.

108. AGS, CC, 465. Consulta, 22/03/1637.

109. Sobre este tipo de préstamos en Flandes. Esteban Estríngana, A.: Guerra y finanzas en los Países Bajos católicos. De Farnesio a Spinola (1592-1633). Madrid, 2002; Esteban Estríngana, A.: «Provisiones de Flandes y capitales flamencos», en Banca, crédito y capital. La Monarquía Hispánica y los antiguos Países Bajos (1505-1700). 2006, pp. 233-274.

110. AGS, CC, 465. Consulta, 22/04/1637.

111. AGS, CC, 465. Memorial, 16/02/1637. Bartolomé propuso que la tomasen sus sobrinos renunciando a los crecimientos y adehalas que pedía Scazuola. Él les ayudaría con 500.000 escudos por vía de factoría.

112. AGS, CC, 465. Consulta, 22/03/1637.

(C) Ediciones Universidad de Salamanca / ®@ Stud. his., H. ${ }^{a}$ mod., 39, n. 1 (2017), pp. 265-299 
El 31 de julio de 1637 Julio César renovó el asiento de Cruzada que comenzaría como era tradicional el primer domingo de Adviento de aquel mismo año ${ }^{113}$. Resulta llamativo el cambio de criterio con respecto a la postura adoptada por el Consejo de Hacienda en 1624. Entonces se le arrebató la Tesorería General a Fiesco, a pesar de la larga experiencia y años de servicio de su casa de negocios para confiársela a una compañía desconocida y que aún no se había establecido en Madrid. Ahora en 1637 se le concedió prioridad al mantenimiento en activo de un importante hombre de negocios, al que este asiento podía salvarle de la quiebra. Mantener el mayor número de banqueros en activo era ya una prioridad para el Consejo de Hacienda, pero también un objetivo cada vez más complicado a mediados del reinado de Felipe IV.

Por desgracia, la firma del asiento de Cruzada no detuvo los rumores que corrían por la Corte sobre las dificultades financieras de Julio César Scazuola. Al contrario, su reputación siguió deteriorándose. En el otoño de 1639 todos los organismos de la Corona que trabajaban con él constataban:

el poco crédito con que corre en el lugar, quando mercaderes o cajeros de asentistas no quieren sus letras ni papeles, obliga a más que mediana seguridad ${ }^{114}$.

En cierto modo, Scazuola acabó probando la misma receta que él le había aplicado a Agustín Fiesco. Su relación con la Junta de la media annata fue especialmente tensa ${ }^{115}$. Algunos asentistas que habían recibido libranzas sobre esa renta en 1638 , no cobraban con puntualidad y tenía que emitir letras para pedir prestado ese dinero. Su deuda en este ámbito superaba los 100.000 ducados. El retraso en los pagos no era la única irregularidad de la que se le acusaba. Los comisarios y corregidores estaban obligados a informar a la contaduría de la media annata de las partidas que entregaban a los correspondientes de Scazuola y, a su vez, él debía informar a la Corona qué hacía con el dinero. Se habían detectado desembolsos no reflejados en los libros de la contaduría y se sospechaba que estaba usando el dinero del rey sin ningún tipo de control por la Real Hacienda ${ }^{116}$. Por más que

113. La provisión pactada consistía en 200.000 escudos en Madrid y Sevilla, 400.000 en Flandes y 44.000 ducados de plata adicionales para enviarlos a Roma y sufragar la construcción de la basílica de San Pedro. AGS, CMC $3^{a}$ época, 116. Asiento, 1637-1643.

114. AGS, CJH, 794. Informe del fiscal, 10/10/1639.

115. En la junta estaban el Arzobispo Inquisidor General, el marqués de Torres, el duque de Campobelo, el licenciado Juan Pardo y Diego Suarez.

116. AGS, CJH, 794. Auto, 12/07/1639. Después de su muerte se modificó la forma de fiscalizar y controlar este ingreso. SANZ AYÁN, C.: «El canon a la nobleza en la Monarquía Hispánica. La media anata de mercedes», en Marcos Martín, A.: Hacer historia desde Simancas. Homenaje a José Luis Rodríguez de Diego. 2011, pp. 705-726.

(C) Ediciones Universidad de Salamanca / ®@ Stud. his., H. ${ }^{a}$ mod., 39, n. 1 (2017), pp. 265-299 
la Junta le había apremiado a mostrar sus libros, nunca lo había conseguido. El rey ordenó entonces abrir una investigación e instó a Scazuola a presentar sus cuentas de los últimos cinco años, pero el banquero alegó que le era imposible hacerlo porque muchos tesoreros de Cruzada, encargados también de cobrar la media annata en sus distritos, aún no le habían enviado esa información ${ }^{117}$. Entre octubre de 1638 y mayo de 1639 se le presionó de muy distintas formas e incluso se le multó con 500 ducados para intentar doblegarlo ${ }^{118}$. No solo se negó a pagar la multa, sino que decidió abandonar Madrid durante cinco días:

dejando sin despacho los libros de la contaduría para que en ellos se admitiesen los recivos de su cajero ${ }^{119}$.

Su actitud resultaba desafiante para muchos consejeros y un mal ejemplo para el resto de banqueros del rey, que estaban obligados a atender todos los días los asuntos que tenían a su cargo y a no salir de la Corte sin el permiso del rey y de los organismos con los que trabajaban habitualmente. Este comportamiento y la debilidad con la que actuó el Consejo solo se entiende en un contexto de extrema necesidad de crédito, pero al mismo tiempo de fragilidad negociadora por parte de la Corona, donde cada vez era más complejo contar con banqueros solventes dispuestos a involucrarse en la negociación de asientos.

Aunque la Corona intentó que Scazuola continuase negociando asientos de dinero a partir de 1637, sin el respaldo de los Fugger su actividad financiera decayó notablemente (tabla 1 y gráfico 1). Su negocio se volcó en gestionar las rentas que administraba, proveyendo dinero dentro de Castilla. El asiento firmado en 1639 por valor de 800.000 escudos ya no le exigía hacer ninguna transferencia al exterior, como había sido habitual hasta entonces. La Real Hacienda se conformaba con que captase dinero en Madrid para pagar al ejército en España y atender los gastos de las Casas Reales ${ }^{120}$.

Scazuola intervino por última vez en la negociación de las Provisiones Generales a finales de 1639, comprometiéndose a proveer 303.000 ducados, una décima parte del total. Sin embargo, no llegó a firmar el contrato porque falleció aquel mismo otoño. Su contribución tuvo que repartirse entre el resto de asentistas porque fue imposible encontrarle un sustituto ${ }^{121}$.

117. AGS, CJH, 794. Memorial, 22/01/1639.

118. AGS, CJH, 794. Memorial, 19/10/1639.

119. AGS, CJH, 794. Informe, 26/03/1639.

120. AGS, CJH, 795. Consulta 19/09/1639. AGS, CJH, 794. Memorial, 1639.

121. AGS, CJH, 795. Consulta, 23/11/1639.

(C) Ediciones Universidad de Salamanca / ®@ Stud. his., H. ${ }^{a}$ mod., 39, n. 1 (2017), pp. 265-299 


\section{La muerte de Scazuola y su Relevo al FRente de su Casa de Negocios}

Julio César murió el 22 de noviembre de 1639 dejando una viuda y ocho hijos legítimos ${ }^{122}$. Gracias a uno de sus últimos asientos con la Corona, Luis Felipe obtuvo una encomienda en el Consejo de Hacienda ${ }^{123}$, y Carlos un hábito en la orden de Calatrava ${ }^{124}$.

La Corona intentó a toda costa mantener en activo su casa de negocios por los asientos que tenía pendientes y porque debía aclarar todas las cuentas atrasadas de la media annata y de la Cruzada. Las rebeliones de Cataluña y Portugal en 1640 iban a complicar aún más la financiación de la guerra con Francia, impidiendo recaudar impuestos en algunas zonas de Castilla. A lo que se sumó el hecho de que entre 1639 y 1640 la Corona no solo perdió a Scazuola, sino que también fallecieron otros importantes banqueros genoveses a los que fue casi imposible sustituir de forma inmediata ${ }^{125}$.

Scazuola no había dejado a ningún heredero que pudiese continuar sus negocios, por lo que fueron los contadores de la Real Hacienda quienes hicieron un primer balance de sus cuentas. La compañía tenía compromisos pendientes que rondaban el millón de ducados (346.543.000 mrs) en base a los contratos que aún tenía vigentes. Unas provisiones con las que se contaba para aquel invierno y para las que no era nada sencillo encontrar un reemplazo. El Consejo de Hacienda designó a una persona «de toda inteligencia y satisfacción (...) para que, enterado de todo, vaya previniendo y disponiendo lo que convenga», y que informase continuamente ${ }^{126}$. Había varios organismos interesados en sus cuentas: el Consejo de Cruzada, la Junta del papel sellado, la Junta de la media anata, así como los diversos jueces y tribunales ordinarios a quienes pronto empezaron a acudir sus clientes y acreedores. Al Consejo le preocupaba que las medidas que todos estos organismos pudiesen adoptar en defensa de sus derechos, dañasen definitivamente el crédito y reputación de la casa de negocios impidiéndola seguir trabajando. Por ese motivo se designó a Pedro de Escobedo responsable de su gestión, teniendo en cuenta su experiencia hasta entonces como tesorero particular de Cruzada en

122. AHPNM, 5982, fol. 442. Transacción, 19/02/1641. La mayor, Isabel María, tenía 14 años, el resto eran aún más jóvenes: Luis Felipe, Catalina, Antonia, Julio, Carlos, María y Andrea. AHN, OM de Caballeros_Calatrava, Exp. 2430.

123. AGS, CJH, 845. Consulta, 30/08/1639.

124. AGS, CJH, 795. Consulta, 20/10/1639. AGS, CJH, Libro 166. Orden, 22/10/1639.

125. Álvarez Nogal, C.: «Las compañías bancarias genovesas en Madrid a comienzos del siglo XVII». Sobre la década de 1640, SAnz Ayán, C.: Los banqueros y la crisis de la Monarquía Hispánica de 1640. Madrid, 2013.

126. AGS, CJH, 795. Consulta, 22/11/1639.

(C) Ediciones Universidad de Salamanca / ®@ Stud. his., H. ${ }^{a}$ mod., 39, n. 1 (2017), pp. 265-299 
Toledo $^{127}$. Su principal misión consistió en cumplir con los compromisos que Scazuola aún tenía pendientes por sus asientos.

Escobedo se hizo cargo no solo de la Cruzada sino también de la media annata de mercedes y del papel sellado. Durante los siguientes tres años fue liquidando todas las cuentas de Julio César con la Real Hacienda ${ }^{128}$. Para ello contó también con el apoyo de los herederos de la compañía «Condes Gerónimo Fucar hermano y primo», a quienes se le debían réditos de juros y deudas de sus antiguos asientos ${ }^{129}$. No logró completar el último asiento de 800.000 escudos firmado por Julio César, ni volvió a comprometerse en ninguna otra provisión. Sus únicas transferencias al exterior consistieron en las sumas a las que le comprometía el asiento de Cruzada ${ }^{130}$. Pedro de Escobedo fue un aplicado gestor, pero nunca se comportó como un banquero.

\section{Conclusiones}

La historia de los Fugger en las finanzas de la Corona española no se reduce solo a la vieja compañía, la heredera de los negocios de Antón y gestora de los Maestrazgos y Almadén. Entre 1624 y 1636 hubo una segunda compañía que maniobró hábilmente en la Corte española con la ayuda de su agente Julio Cesar Scazuola, arrebatándole primero la administración de la Cruzada a Agustín Fiesco, una de las casas genovesas más destacadas de aquel momento, y después convirtiéndose en uno de los pilares esenciales de la negociación crediticia en la década de 1630.

Su incorporación a los asientos se produjo incluso antes de que llegasen los banqueros portugueses, incrementando así la competencia entre los banqueros del rey que tanto ansiaba el conde-duque de Olivares. El asiento de Cruzada fue la excusa perfecta para instalarse en Madrid y controlar otros importantes ingresos reales como la media annata de mercedes y el papel sellado. Les afectó el decreto de 1627 como al resto de banqueros, pero esa medida no les impidió desarrollar una enorme actividad financiera prestando más de 14 millones de ducados durante los 14 años que la compañía estuvo abierta en Madrid.

Los Fugger jóvenes no dispusieron de un acceso directo a las ferias de cambios italianas como los banqueros genoveses, pero lograron financiar sus contratos acuñando vellón, captando depósitos de pequeños ahorradores y descontando

127. Se le nombró «Administrador general de la casa y negocios de Julio César Scazuola». AHPNM, 7334, fol. 217. Escritura, 17/07/1641.

128. AGS, CJH, 806. Consulta, 3/02/1640.

129. AHPNM, 7334, fol. 153v. Poder, 18/04/1640.

130. AGS, CJH, 845. Consulta, 29/04/1642.

(C) Ediciones Universidad de Salamanca / ®@ Stud. his., H. ${ }^{a}$ mod., 39, n. 1 (2017), pp. 265-299 
las libranzas de sus asientos entre quienes recaudaban impuestos en Castilla. Esto explica su dependencia del asiento de Cruzada y, sobre todo, de su red de agentes y tesoreros. Gracias a ellos, la compañía alemana accedió a la plata que circulaba por la península Ibérica, trasladando por vía de descuento el riesgo de sus contratos con la Corona a inversores repartidos por toda Castilla.

Tras la muerte de varios socios, la compañía de los Fugger jóvenes cerró su oficina en la Corte en 1636, una vez concluido el segundo asiento de Cruzada. Julio César Scazuola continuó entonces por su propia cuenta hasta que finalmente falleció en noviembre de 1639. Para entonces, la casa de los Fugger viejos también había cerrado sus puertas y la Corona buscaba administradores que pudiesen gestionar las rentas que, hasta entonces, habían controlado las dos compañías alemanas que trabajaron para Felipe IV.

\section{Bibliografía}

Aldea Vaquero, Q.: España y Europa en el siglo XVII. Correspondencia de Saavedra Fajardo. Madrid, 1986.

Almansa y Mendoza, A. D.: Cartas. Novedades de esta corte y avisos recibidos de otras partes, 1.621-1.626. Madrid, 1886.

Álvarez Nogal, C.: Los banqueros de Felipe IV y los metales preciosos americanos (16211665). Madrid, 1997.

Álvarez Nogal, C.: «El Factor General del Rey y las Finanzas de la Monarquía Hispánica», Revista de Historia Económica, 3, 1999, pp. 507-539.

Álvarez Nogal, C.: «La estrategia de la Real Hacienda en la negociación del crédito de los Austrias», en Bernal, A. M.: Dinero, moneda y crédito en la Monarquía Hispánica. 2000, pp. 437-456.

Álvarez Nogal, C.: «Los problemas del vellón en el siglo XviI. ¿Se consiguió abaratar la negociación del crédito imponiendo precios máximos a la plata?», Revista de Historia Económica, 2001, pp. 17-37.

Álvarez Nogal, C.: «Las compañías bancarias genovesas en Madrid a comienzos del siglo XVII», Hispania, 219, 2005, pp. 67-90.

Álvarez Nogal, C.: «L'argent du Roi et les hommes d'argent», en Dubet, A.: Administrer les finances dnas la Monarchie Espagnole. 2008, pp. 187-198.

Álvarez Nogal, C.: «The Role Played by Short-run Credit in the Spanish Monarchy's Finances», en Piola Caselli, F. E.: Government Debts and Financial Markets in Europe. 2008, pp. 81-97.

Andrés UCENDO, J. I. y LANZA García, R.: «Estructura y evolución de los ingresos de la Real Hacienda de Castilla en el siglo XVII», Studia Historica. Historia Moderna, 30, 2008, pp. 147-190.

Boyajian, J. O.: Portuguese Bankers at the Court of Spain 1626-1650. Nueva Jersey, 1983. Carande, R.: Carlos Vy sus banqueros. Barcelona, 1987.

(C) Ediciones Universidad de Salamanca / ®@ Stud. his., H. ${ }^{a}$ mod., 39, n. 1 (2017), pp. 265-299 
Carlos Morales, C. J. D.: El precio del dinero dinástico: Endeudamiento y crisis financieras en la España de los Austrias, 1557-1647. Madrid, 2016.

Castillo Martos, M.: «Bartolomé de Medina introduce la amalgamación en Nuevas España», en Castillo Martos, M. y LANG, M. F.: Metales preciosos: unión de dos mundos. 1995, pp. 96-105.

Domínguez Ortiz, A.: Política y Hacienda de Felipe IV. Madrid, 1960.

Elliott, J. H.: El Conde-Duque de Olivares. Barcelona, 1991.

Esteban Estríngana, A.: Guerra y finanzas en los Países Bajos católicos. De Farnesio a Spinola (1592-1633). Madrid, 2002.

Esteban Estríngana, A.: «Provisiones de Flandes y capitales flamencos», en Banca, crédito y capital. La Monarquía Hispánica y los antiguos Países Bajos (1505-1700). 2006, pp. 233-274.

Fernández de Pinedo, E.: El Censo de la Sal (1631). Hacienda y consumo. Bilbao, 2014.

García Guerra, E. M.: Las acuñaciones de moneda de vellón durante el reinado de Felipe III. Madrid, 2000.

Goñi Gaztambide, J.: Historia de la bula de la Santa Cruzada. Vitoria, 1958.

Graulau, J.: «Finance, Industry and Globalisation in the Early Modern Period: the example of the metallic business of the House of Fugger», Rivista di Studi Politici Internazionali, 300, 2008, pp. 554-598.

Grendi, E.: I Balbi. Torino, 1997.

Harreld, D. J.: High Germans in the Low Countries: German Merchants and Commerce in Golden Age Antwerp. Boston, 2004.

Hering, E.: Los Fúcar. México, 1944.

KARG, F.: «Jacob Fugger, comerciante, banquero, fundador. Los archivos Fugger», en Sánchez del Barrio, A.: Francesco Datini, 1335-1410, Jacob Fugger, 1459-1525, Simón Ruiz, 1525-1597: los legados histórico artísticos y documentales de tres grandes hombres de negocios. 2009, pp. 135-152.

Kellenbenz, H.: «Los Fugger en España en la época de Felipe II. ¿Fue un buen negocio el arrendamiento de los maestrazgos después de 1562?», en OTAZu, A.: Dinero y Crédito (siglos XVI al XIX). 1978, pp. 19-36.

Kellenbenz, H.: «Los Fúcar en España y Alemania: un tema de historia comparada», en Actas del Simposio sobre posibilidades y limites de una historiografía nacional. 1984, pp. 161-176.

Kellenbenz, H.: Los Fugger en España y Portugal hasta 1560. Salamanca, 2000.

LANG, M. F.: El monopolio estatal del mercurio en el México colonial. México, 1978.

Lohman Villena, G.: Los americanos en las ordenes nobiliarias. Madrid, 1993.

Marcos Martín, A.: «Tráfico de indulgencias, guerra contra infieles y finanzas regias. La bula de Cruzada durante la primera mitad del siglo XVII», en RODRíGUEZ CANCHO, M.: Historia y perspectivas de investigación. Estudios en memoria del profesor Ángel Rodríguez Sánchez. 2002, pp. 227-236.

Marsilio, C.: Dove il denaro fa denaro. Glio operatori finanziari genovesi nelle fiere di cambio del XVII sécolo. Novi Ligure, 2008.

(C) Ediciones Universidad de Salamanca / 요 Stud. his., H. ${ }^{a}$ mod., 39, n. 1 (2017), pp. 265-299 
Motomura, A.: «The Best and Worst of Currencies: Seigniorage and Currency Policy in Spain, 1597-1650», Journal of Economic History, 1, 1994, pp. 104-127.

Nebinger, G. y Rieber, A.: Genealogie des Hauses Fugger von der Lilie. Tübingen, 1978.

Ojeda Nieto, J.: «La población de Castilla y León en el siglo XVII: un intento de aproximación demográfica a través de la bula de la Santa Cruzada», Studia Historica. Historia Moderna, 22, 2000, pp. 109-144.

PArker, G.: El ejército de Flandes y el Camino Español 1567-1659. Madrid, 1986.

Roover, R. D.: Business, Banking and Economic Thought in Late Medieval and Early Modern Europe. Chicago, 1974.

Ruiz MarTín, F.: Las finanzas de la monarquia hispánica en tiempos de Felipe IV (16211665). Madrid, 1990.

SANZ AYÁn, C.: «"Prestar, regalar y ganar”. Dinero y mecenazgo artístico-cultural en las relaciones entre la Monarquía Hispánica y Florencia (1579-1647)», en Banca, crédito y capital: La Monarquía Hispánica y los antiguos Países Bajos, 1505-1700. 2006, pp. 459-483.

SAnZ AyÁn, C.: «El canon a la nobleza en la Monarquía Hispánica. La media anata de mercedes», en Marcos Martín, A.: Hacer historia desde Simancas. Homenaje a José Luis Rodríguez de Diego. 2011.

SAnZ Ayán, C.: Los banqueros y la crisis de la Monarquía Hispánica de 1640. Madrid, 2013.

TAYlor, H.: «Trade, Neutrality, and the "English Road” ", 1630-1648», Economic History Review, 2, 1972, pp. 236-260.

UlloA, M.: La Hacienda Real de Castilla en el reinado de Felipe II. Madrid, 1977.

Voltes, P.: «Aportación a la historia de las operaciones de los Fugger en España durante el XVII», Moneda y Crédito, 1961, pp. 13-40.

(C) Ediciones Universidad de Salamanca / 요 Stud. his., H. ${ }^{a}$ mod., 39, n. 1 (2017), pp. 265-299 
